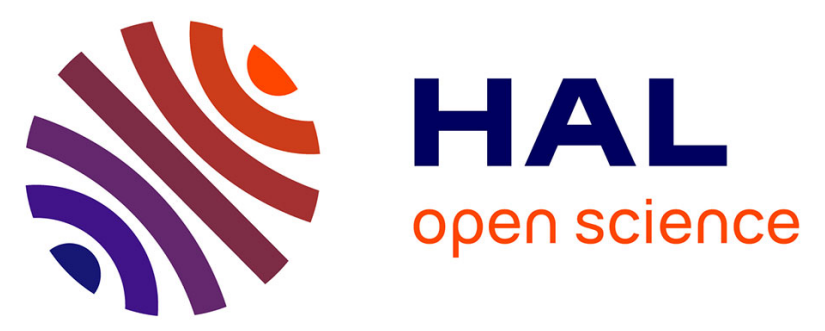

\title{
SOLID/GAS BIOREACTORS: POWERFUL TOOLS FOR FUNDAMENTAL RESEARCH AND EFFICIENT TECHNOLOGY FOR INDUSTRIAL APPLICATIONS.
}

Sylvain Lamare, Marie-Dominique Legoy, Marianne Graber

\section{- To cite this version:}

Sylvain Lamare, Marie-Dominique Legoy, Marianne Graber. SOLID/GAS BIOREACTORS: POWERFUL TOOLS FOR FUNDAMENTAL RESEARCH AND EFFICIENT TECHNOLOGY FOR INDUSTRIAL APPLICATIONS.. Green Chemistry, 2004, 6, pp.445-458. hal-00329713

\section{HAL Id: hal-00329713 \\ https://hal.science/hal-00329713}

Submitted on 13 Oct 2008

HAL is a multi-disciplinary open access archive for the deposit and dissemination of scientific research documents, whether they are published or not. The documents may come from teaching and research institutions in France or abroad, or from public or private research centers.
L'archive ouverte pluridisciplinaire HAL, est destinée au dépôt et à la diffusion de documents scientifiques de niveau recherche, publiés ou non, émanant des établissements d'enseignement et de recherche français ou étrangers, des laboratoires publics ou privés. 
SOLID/GAS BIOREACTORS: POWERFUL TOOLS FOR FUNDAMENTAL RESEARCH AND EFFICIENT TECHNOLOGY FOR INDUSTRIAL APPLICATIONS.

LAMARE Sylvain*, LEGOY Marie Dominique and GRABER Marianne

Laboratoire de Biotechnologies et de Chimie Bio-organique, Bâtiment Marie Curie, Université de La Rochelle, Avenue Michel Crépeau, F-17042 cedex 1.

Email : slamare@univ-lr.fr

ILLUSTRATED CONTENTS.

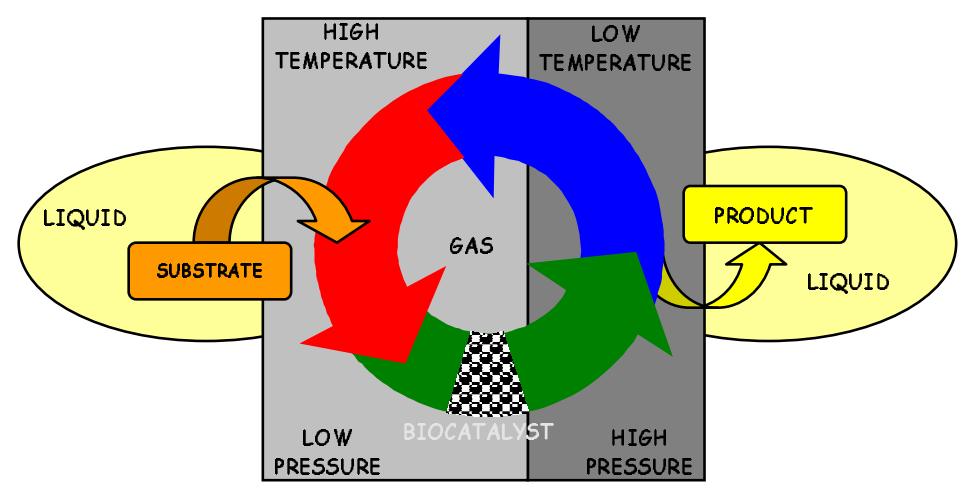

Solid/gas biocatalysis, is based on a total thermodynamic control of the reactions, compared to liquid systems. With this system, involving a biocatalyst as a solid phase acting on gaseous substrates, it is possible to modulate and to study the effect of each component present in the microenvironment of the catalyst. Solid gas catalysis appears also as a new clean technology for better bioprocesses. 


\section{SUMMARY.}

Solid/gas biocatalysis appears today as a promising technology for fundamental research and for the development of new cleaner industrial processes. The use of enzymes or whole cells at the solid/gas interface appears now concurrent to liquid processes and presents some very interesting features since total thermodynamic control of the system can be achieved easily. Moreover, on a technological point of view, solid/gas systems offer very high productivity for minimal plant sizes, allow important reduction of treated volumes and permit simplified downstream processes.

These advantages result from the ability to control precisely all the thermodynamic parameters influencing not only the kinetics of the reactions performed, but also the stability of the biocatalysts working in a continuous way at temperatures far higher from the temperatures encountered in nature.

In this article, an overview of some existing systems and application of solid/gas technology to fundamentals studies related to the influence of the microenvironment on biocatalyst is given. The potential of this peculiar system, and examples of applications that should get benefits of the technology are presented herein.

Keywords: Solid/Gas, Biocatalysis, Process, Enzyme, Cell 


\section{INTRODUCTION.}

Non conventional enzymology cannot only be resumed to the use of enzymes in monophasic organic systems. During the last decades, new technologies in the field of enzymatic catalysis have been developed, such as multiphasic systems, micro emulsions or micellar systems. Lately, the use of supercritical fluids or solid/gas catalysis have been tested and implemented for new biotechnological processes.

Solid /gas catalysis presents many advantages compared to other systems (i.e. liquid, mono or biphasic ones). Its strength results from the possibility to obtain very high conversion yields compatible with a high productivity for a minimal plant scale, considering that: mass transfers are more efficient at the solid/gas interface, enzymes and cofactors are more stable in systems with restricted water availability, problems of solubility of substrates and products do not exist, the use of solvent can be avoided

Moreover, because the solid/gas catalysis is synonymous with the use of higher temperatures, microbial contamination of the bioreactor can be avoided.

Finally, the downstream process is simplified due to the absence of a solvent phase and the scale-up operation for such a process is simpler due to the use of a gaseous circulating phase.

Although this system presents very interesting features, the technology in which biocatalysts are suspended in mixtures of substrates and water vapors remains relatively unexplored in contrast to those where enzymes are placed directly in aqueous or non aqueous solvents. One of the major result obtained from first studies on such systems, was to prove that biocatalysts, traditionally functioning in liquid systems, were able to bind and to transform molecules present in a gaseous phase since there was only one example of an enzyme acting on gaseous substrates, reported in the literature. 
Hydrogenase is a unique enzyme whose substrate is gaseous hydrogen. Yagi and collaborators ${ }^{1}$ have clearly demonstrated that hydrogenase in the dry state binds the hydrogen molecule and renders it activated, resulting in parahydrogen-orthohydrogen conversion, whereas, aqueous protons do not participate in the reaction mechanism.

In a subsequent paper Kimura et $a l^{2}$ proved that, using purified hydrogenase, it was possible to obtain not only the conversion and exchange reactions, but also the reversible oxidoreduction of the electron carrier, cytochrome c3 with $\mathrm{H}_{2}$.

From the middle of the 80 's, examples of gas/solid systems using either entire cells or isolated enzymes were reported in the literature, demonstrating that solid/gas biocatalysis was also possible with enzymes usually acting on liquid substrates. These systems were involving either isolated enzymes or whole cells for mono or multi steps reactions. Different isolated enzymes were tested successfully such as the horse liver dehydrogenase ${ }^{3}$, the Sulfolobus solfataricus dehydrogenase ${ }^{4}$, the Pischia pastoris alcohol oxidase ${ }^{5,6}$, the baker's yeast alcohol dehydrogenase ${ }^{7}$ and finally lipolytic enzymes ${ }^{8-12}$.

Entire cells were also used in solid/gas systems such as Methylocystis $s p^{13}$, Pseudomonas putida $^{14}$, Saccharomyces cerevisiae ${ }^{15}$ or Rhodococcus erythropolis ${ }^{16}$, mainly for the bio remediation of VOCs polluted gases.

This research area led to the definition of new continuous cleaner processes for single or multi steps biotransformations, involving either enzymatic solid/gas bioreactors or microbial set-ups. Nevertheless, as briefly described below, efficient thermodynamic control of the different operating parameters appears crucial in order to rationalize the kinetics of biocatalysts in solid/gas systems and to stabilize these systems for larger scale applications. 


\section{Operating solid/gas systems:" the water activity paradox".}

The impact on biocatalysis of very high substrate concentrations or of the addition of organic solvents in liquid systems have been extensively studied in the last decades. Numerous publications reported the effect of physico-chemical modifications of the microenvironment onto catalysis and stability of enzymes in non conventional media, and consequently highlighted the importance of water on enzymatic catalysis ${ }^{17-19}$.

In 1985 , Drapron ${ }^{20}$ made the following recommendation: "... Observations on enzymatic transformations in food of low water content were in some cases concerned with the activity of enzyme multisystems in which microbiological and chemical reactions may be involved. In this case it was often difficult to differentiate between enzymatic and non enzymatic influences. Sometimes, only the absolute water content was taken into account, although it is now clear that these phenomena must be related to the state of water which is described by the water activity $\left(\mathrm{a}_{\mathrm{W}}\right)$ of the medium. Thus, the enzyme activities and kinetics could not be obtained, regardless of whether water was involved as a reactant (hydrolysis) or in an other way..."

and he concluded by the following :"...Although enzyme activity in media with low water content generally has different properties to that observed in dilute aqueous solutions, the classical laws of enzymes kinetics seem to be applicable. However, it is necessary to take into account the thermodynamic state of water which is a fundamental factor influencing enzyme activity in low water content media".

Thus, water activity was reported to be the key parameter in non conventional biocatalysis. Consequently, the effect of water activity onto catalysis and stability constituted, in most of the published works, the core of all the studies devoted to solid/gas biocatalysis. 
Ethanol oxidation in gaseous phase in batch reactors using Pichia pastoris alcohol oxidase reported by Barzana et al, ${ }^{5,6}$ showed that dehydrated enzyme immobilized on DEAE cellulose or on controlled pore glass beads was able to oxidize methanol and ethanol vapors at elevated temperatures, in absence of water in the gas phase. Nevertheless, the study on the effect of the water activity showed that enzyme activity in the gas phase increases by several orders of magnitude, whereas the thermostability decreases drastically when water activity $\left(a_{\mathrm{W}}\right)$ is increased from 0.11 to 0.97 .

Similar conclusions were drawn from the studies on alcohol dehydrogenases in a solid-gas bioreactor for alcohol and/or aldehyde production, ${ }^{3,4}$ using alcohol dehydrogenase and $\mathrm{NAD}^{+}$(or $\mathrm{NADH}, \mathrm{H}^{+}$) co-immobilized into albumin-glutaraldehyde porous particles in batch and continuous fed column reactors. An aldehyde reduction was coupled to a second alcohol oxidation in order to regenerate the cofactor.

As well, water activity was the key parameter in studies concerning other types of enzymes tested in solid-gas reaction such as lipases or esterases. Candida rugosa lipase and other esterolytic enzymes coated on glass beads ${ }^{21}$ and suspended in mixtures of substrates and water vapors over a range of water activity from 0.56 to 1 showed the ability to perform different reactions, and the extent of reaction was classified in the following order, for decreasing $\mathrm{a}_{\mathrm{W}}$ values:

$$
\text { hydrolysis }>\text { alcoholysis }>\text { ester exchange }>\text { esterification. }
$$

Robert et $a l^{12}$ showed the relationships existing between water activity, the hydration state characterized by the sorption isotherm of the catalytic preparation and the activity /stability of a lipase used in a continuous solid/gas system for a transesterification reaction. 
Water activity effects were also extensively studied for solid/gas systems involving whole cells as catalysts. Fifteen years ago, the, epoxidation of alkenes by bacteria has received many attention, in view of the possible production of certain epoxides by mean of a biotechnological process. A solid-gas bioreactor has been used to promote a rapid and continuous removal of the toxic ethylene oxide from the environment of the immobilized cells of Mycobacterium Py 1 in alginate beads and on sand. The conversion of propylene or ethylene to the corresponding oxide was performed by a mono-oxygenase system needing molecular oxygen and $\mathrm{NADH}, \mathrm{H}^{+}$or $\mathrm{NADPH}, \mathrm{H}^{+}$. The cofactor regeneration was reported to be possible through endogenous respiration. The influence of immobilization and reduced water activity was studied, on gaseous-alkene oxidation by the same type of organism in a solid-gas bioreactor by Hamstra et al. ${ }^{22}$ Similarly, continuous production of propylene oxide was successfully demonstrated using a simple solid-gas heterogeneous bioreactor with Methylosinus sp CRL 31 coated onto porous glass beads ${ }^{23}$ working at $40^{\circ} \mathrm{C}$ at an optimal water activity of 0.7 .

VOCs removal in polluted gases was the second major research topic developed involving solid/gas catalysis. Trichloroethylene, one frequent gaseous contaminant, has been shown to be degraded by immobilized resting cells of Methylocystis sp $\mathrm{M}$ in the same kind of reactor. ${ }^{13}$ The catalytic activity was found to decrease rapidly as water activity was lowered. Alcohol oxidase activity of extruded pellets of Pichia pastoris has been tested for vapor phase oxidations by Duff and Murray ${ }^{24}$, at different water activities to the end of production or removal of organics. More recently, Erable et $a l^{16}$ reported the use or Rhodococcus erythropolis cells for the dehalogenation of chloro and bromo alkanes and studied the effect of water activity on stability and catalysis 
All these examples briefly listed above, dealing with the influence of water activity on biocatalysts in solid/gas systems constitute "the water activity paradox".

While the authors in their majority noted that the degree of conversion, the observed reaction rates, and the catalyst stability were highly influenced by the hydration state of the biocatalyst and concluded to the crucial impact of the water activity, all the other constituents (substrates, products, effectors...) were characterized in terms of volumetric concentrations or partial pressures but rarely in terms of thermodynamic activity.

Surprisingly, for many years the use of the thermodynamic activity was recommended for quantifying the substrate availability in non-conventional media, such as liquid organic media ${ }^{25,26}$. Indeed in such media, the "availability of substrate to the enzyme" cannot be quantified using its concentration mainly because substrate solvation is modified as the reaction medium changes. Replacement of concentrations of species by their thermodynamic activities in liquid media requires the knowledge of their activity coefficients ( $\gamma$ values). This is far from being straightforward, as $\left.1^{\circ}\right) \gamma$ values depend on molar ratios of other species present in the medium and $2^{\circ}$ ) methods used to estimate these values such as UNIFAC group contribution method ${ }^{27}$ are often called into question, as sources of inaccuracy ${ }^{28,29,30}$.

In the solid-gas technology however, thermodynamic activity of each compound can be precisely determined by calculating the ratio of the partial pressure of the compound in the gas to its saturation vapor pressure at the working temperature. As explained below partial pressure is obtained from molar composition of the inlet gas and the total pressure, assuming that a poorly charged inert inlet gas can be considered as an ideal gas.

Moreover in solid-gas reactors molar fraction of the different species in the inlet gas can be chosen independently. As a result thermodynamic activities of the different species can be 
fixed independently very easily. This constitutes a significant advantage over solid-liquid system, in which reaction species and solvent molar fractions are linked together and for which totally inert liquid solvents do not exist.

Since total thermodynamic control was easily achievable in solid/gas systems, the concept of working at controlled thermodynamic activity for all the constituents only aroused in the mid 90's ${ }^{8,9}$ Thus, this thermodynamic approach allows to improve the control and then the understandings on solid/gas systems. It is now clear that the ability to control independently each thermodynamic activity constitutes the major advantage of solid/gas systems, as it will be discussed later in this paper.

Then, solid/gas systems represent a powerful tool of investigation concerning the relationships existing between biocatalysts and their microenvironment, and its influence on catalytic activity and stability.

THEORY AND PRACTICE.

The advantage of solid/gas catalysis: a system which permits independent control of the thermodynamic activity of the different chemical species in the microenvironment of the catalyst. 
If one considers a solid/gas bioreactor based on a packed bed, the following representation can be done, as depicted on figure 1 . Then, very simple parameters, controlling the thermodynamic activity of each compound can be easily identified.

The inlet gas will be characterized, by its molar composition, the inlet temperature and the total pressure of the system. For poorly charged gas, if one assumes that it can be considered as an ideal gas, these few parameters allow a complete definition of the thermodynamic parameters of the gas entering the reactor.

While the molar composition of the inlet gas and the total pressure are known, it is possible to calculate easily the partial pressure of each compound $\left(P p_{x}\right)$, resulting from the following equation:

$$
P p_{x}=\frac{n_{x}}{n_{\text {total }}} P a=\frac{Q_{x}}{Q_{\text {total }}} P a
$$

assuming that $n_{x}$ is equal to the number of moles of $\mathrm{X}$ in a finite gas volume containing a total of $n_{\text {total }}$ moles at the absolute pressure of $P a$. For continuous systems, the molar flow $Q$ can be used instead of $n$. Then, the thermodynamic activity $\left(a_{x}\right)$ can be calculated, by using the saturation pressure of the pure compound, obtained from the saturation curves at the temperature of the gas stream $\left(\mathrm{T}_{\mathrm{in}}\right)$ as described in figure 2 and using the following equation:

$$
a_{x}=\frac{P p_{x}}{P p s a t_{x}}
$$

Two main strategies can be used for creating a gas with fixed thermodynamic activity, based either on the saturation by an organic molecule of a carrier gas or by vaporization of liquid molecules using a liquid/gas flash operation in an inert carrier flow. The reactors described in the literature use in their majority the first approach, and simple calculations and controls allow a precise control of all the operating parameters of solid/gas systems. 
If one considers the following bioreactor (depicted on figure 3) in which, different saturated gases are mixed for the realization of the final gas, the control of operational parameters can be realized as indicated below.

\section{Creating a gas: the saturated gases mixing technique.}

One can assume that a carrier gas, after bubbling in a substrate solution at controlled temperature, is in equilibrium with the liquid phase and so, the partial pressure of the substrate in the gas leaving the saturation apparatus is equal to the vapor pressure corresponding to the saturation pressure above the pure compound at a given temperature. In order to calculate the composition of the gas, the different molar flows for each compound (carrier + substrates + water) have to be known. The molar carrier flow in each line is calculated when having access to the volumetric normalized flows $(273,15 \mathrm{~K}, 1 \mathrm{~atm})$ of carrier gas used for saturation:

$$
Q_{N_{2}}^{n}=\frac{Q v_{N_{2}}^{n} \text { normalized }}{R . T}(\mathrm{~mol} / \mathrm{h} \text { for } \mathrm{T}=273.15 \mathrm{~K})
$$

Then, with the knowledge of the molar flow of the carrier gas it becomes possible to calculate the different molar flows leaving the saturation flasks by the formula using the saturation pressure:

$$
Q_{X}^{n}=Q_{N_{2}}^{n} \frac{P p s a t_{X}^{n}}{\left(P a-P p s a t_{X}^{n}\right)}(\mathrm{mol} / \mathrm{h})
$$

with Ppsat $_{X}^{n}$ determined at the temperature of saturation

After mixing the different lines, the partial pressure of each compound in the gas entering the bioreactor is determined using: 


$$
P p_{X}^{n}=\frac{Q_{X}^{n}}{\sum_{1}^{n}\left(Q_{N_{2}}^{n}+Q_{X}^{n}\right)} P a(\mathrm{~atm})
$$

and the activity of each compound in the reactor stage is calculated as follows:

$$
a_{x}=\frac{P p_{X}^{n}}{P p s a t_{X}^{n}} \text { with Ppsat }{ }_{X}^{n} \text { determined at the temperature of the bioreactor. }
$$

Assuming that the applied conditions are far from the critical temperature and the critical pressure for each compound, and by applying the ideal gas law P.V = n.R.T, one can have a good estimation of the total volumetric flow and the residence time in the bioreactor.

$$
Q v_{\text {total }}=\frac{R T \sum_{1}^{n}\left(Q_{N_{2}}^{n}+Q_{X}^{n}\right)}{P a}\left(1 / \mathrm{h} \text { at the temperature of the bioreactor in }{ }^{\circ} \mathrm{K}\right)
$$

\section{Creating a gas: the vaporization of organics in a carrier gas technique.}

When a liquid/gas flash vaporization technique is chosen, then a precise control of the different molar flows of each molecules entering in the composition of the gas must be realized. Figure 4 describes a solid/gas setup in which, liquid substrates, water and nitrogen are injected in a flashing unit for the realization of the gas. ${ }^{10}$

Then, thermodynamic control is realized, by calculating the different partial pressures based on the different molar flows. While $Q_{N_{2}}$ and $Q_{x}^{n}$ are well known, then $Q_{\text {total }}=Q_{N_{2}}+\sum_{1}^{n} Q_{X}^{n}$ can be determined and partial pressures can be calculated easily by the following equation,

$$
P p_{X}^{n}=\frac{Q_{X}^{n}}{Q_{\text {total }}} P a
$$


and thermodynamic activities are calculated, according to equations previously described.

Although the system brings a better control of the molar flows of substrates compared to the previous system described, care must be taken in order to insure a complete vaporization of the different molecules injected in the system. To this end, saturation pressure curves (Vapor Liquid Equilibriums) have to be known for defining the minimal temperature that has to be used at the flashing level. This point can be considered as a bottleneck, since in some cases, the use of very high temperatures can represent a serious constraint. Nevertheless, this problem can be solved by performing solid/gas catalysis under reduced pressure. This strategy offers multiple advantages for the use of longer chain length compounds or for the improvement of productivity. The use of reduced pressure allows a important enrichment of the gaseous phase in reactants while minimizing greatly the carrier gas needed and the required flashing temperature.

Variations of working absolute pressure: an easy way to improve solid/gas systems.

As an example, one can compare the effect of pressure on a simple theoretical transformation

Considering a simple transformation of $\mathrm{X}$ to $\mathrm{Y}$ carried out at $100^{\circ} \mathrm{C}$ and $\mathrm{a}_{\mathrm{x}}=\mathrm{a}_{\mathrm{w}}=0.1$, with a saturation pressure of $\mathrm{X}$ at $100^{\circ} \mathrm{C}$ of 0.2 atm and of 1 atm for water; boiling point of $\mathrm{X}$ is $200^{\circ} \mathrm{C}$ at $1 \mathrm{~atm}$, then, $P p_{X}$ will be set to 0.02 atm and $P p_{H 20}$ will be 0.1 atm in the inlet gas. The total molar flow will be 100 moles/h, and the reaction will be carried out at two absolute pressure, 0.2 atm and 1 atm.

The characteristics of the two gases are summarized in table 1. 
The benefit of a reduced absolute pressure is then clearly established, since the gas at $0.2 \mathrm{~atm}$ is highly charged in $\mathrm{X}$ molecules, while the nitrogen consumption is divided by a factor of 2.2 for a productivity increased by a factor of 5 compared to the system functioning at atmospheric pressure. Flashing temperature is also lowered by the use of a reduced pressure, thus minimizing the energy required for this operation.

Nevertheless, if one compares the two systems at the same productivity level, the advantages of the reduced pressure is still significant. While total volumetric flow and molar flows for $\mathrm{X}$ and water will be the same in both cases, the required amount of nitrogen will be now 5 times lower at reduced pressure. Thus, nitrogen consumption is divided by a factor of 11 compared to a system at atmospheric pressure for the same productivity.

The use of solid/gas systems functioning at reduced pressure is also of great importance considering the step following the catalysis consisting in the recovery of the products. If one considers now that after catalysis, the gas stream is cooled at $10^{\circ} \mathrm{C}$ under an absolute pressure of $1 \mathrm{~atm}$ for the recovery of the product $\mathrm{Y}$, and that saturation pressure of $\mathrm{Y}$ at $10^{\circ} \mathrm{C}$ is $0,01 \mathrm{~atm}$, then, the system depicted on figure 4 allows a better recovery of $\mathrm{Y}$, while it is very low for the system depicted on figure 3 .

If all $\mathrm{X}$ is transformed into $\mathrm{Y}$, then, on both systems, the gas at the outlet of the reactor will have the following characteristics at the steady state: $P p_{H 2 O}=0.1$ atm, $P p_{X}=0$ atm, $P p_{Y}=0.02$ atm.

Prior the cooling operation, the gas on system described on figure 4 will have an absolute pressure at the outlet of the vacuum pump of 1 atm. Then, in this case, the characteristics will be prior the inlet of the condenser: $P p_{H 20}=0.5$ atm, $P p_{X}=0$ atm, $P p_{Y}=0.10$ atm since $P a$ is multiplied by a factor of 5 . 
Once cooled at $10^{\circ} \mathrm{C}$, the condensation will take place, while the partial pressure of $\mathrm{Y}$ is higher than the saturation pressure of $\mathrm{Y}$ at $10^{\circ} \mathrm{C}$. Thus, the efficiency will be completely different in the two cases. For the reactor working at atmospheric pressure, only $50 \%$ of $\mathrm{Y}$ will be condensed $\left(\frac{P p_{Y}-P p s a t_{Y}}{P p_{Y}}=\frac{0.02-0.01}{0.02}=0.5\right)$ while $90 \%$ of $\mathrm{Y}$ will be condensed $\left(\frac{P p_{Y}-P p s a t_{Y}}{P p_{Y}}=\frac{0.1-0.01}{0.1}=0.9\right)$ for the system working at $0.2 \mathrm{~atm}$.

Absolute pressure then appears also as crucial as temperature for optimizing such systems since thermodynamic properties of gases are highly dependent on Pressure and Temperature parameters.

\section{Thermodynamic activity and the hydration/solvatation equilibrium of the catalyst.}

When using thermodynamic activity, care must be taken since this is an equilibrium parameter. Halling ${ }^{31}$ illustrated clearly the equilibriums existing in a multiphasic system. In solid/gas systems, the equilibrium between the solid phase and the gaseous phase is crucial, since it defines the true solid/gas character.

Any solid phase, when placed in a gaseous environment containing a chemical species at a given thermodynamic activity, will be able, depending on its physico-chemical properties to adsorb molecules up to reach an equilibrium.

Likely to water, any compound can compete for some adsorption sites onto a biocatalyst thus having different interaction states and levels.

Experiments performed by Yang and Rupley ${ }^{32}$ related to the interactions of water molecules with solid proteins brought numerous highlights concerning the processes involved. They showed that the hydration of lysozyme was a sequential process, with a controlled 
distribution of water molecules onto the protein. By using a micro calorimetric technique, they followed the evolution of the specific heat $\left(\mathrm{C}_{\mathrm{p}}\right)$ of a powder of lysozyme under different hydration conditions. The results, presented on figure 5 allow to distinguish between 4 regions.

By taking into account the difference between the global $\mathrm{C}_{\mathrm{p}}$ and the $\mathrm{C}_{\mathrm{p}}$ of lysozyme and water, they gave the following description of the sequence of events taking place when raising the water content of the powder :

- in region IV, the $C_{p}$ of water is very close of the one of ice, traducing a very high organization degree. They also observed a lot of proton exchanges between water and the ionic groups of the protein.

- region III corresponds to the binding of water molecules onto amines and carboxylic groups. The variation of $\mathrm{C}_{\mathrm{p}}$ close to $0.25 \mathrm{~g} \mathrm{H} \mathrm{H}_{2} \mathrm{O} / \mathrm{g}$ protein corresponds to the complete coverage of sites involved in $\mathrm{H}$ bonds, and to the simultaneous appearance of less structured water molecules.

- in the phase II water still continues to cover the protein but without any specific interactions.

- then, region I corresponds to a protein in aqueous solution.

This interactions can also be characterized by the determination of the isotherm sorption curve of the solid preparation (figure 6), by plotting the variation of water content versus the water activity as reported by Drapron ${ }^{20}$ and Hahn-Hagerdäl. ${ }^{33}$

Typically, isotherms present two characteristic break points (A and B) corresponding to two important states of water.

- Before the point A, the water is highly structured. Water molecules are located on ionic groups and polar groups. They constitute what was earlier called the first hydration 
"layer". The point $\mathrm{O}$ corresponds to the tightly bound water (or structural/buried water)

- Between A and B, the water content changes in a linear way while increasing the $\mathrm{a}_{\mathrm{w}}$. It corresponds to the formation of new hydration layers. The protein dissolve molecules of water, thus forming a solid solution.

- The point B corresponds to the appearance of free water. Once the water activity is higher than the abscissa value of point $\mathrm{B}$, an aqueous phase exits, with lots of water molecules having no interaction with the protein. The point $\mathrm{C}$ corresponds to the total quantity of non solvent water, i.e. structured by the solid sample.

Since each molecule present in the gas phase will be able to compete for adsorption onto the catalyst, isotherms resulting from the use of multi components systems may greatly vary depending on the thermodynamic activities used in the gaseous phase. This competition for adsorption onto the solid seems to be the key for understanding the observed effects on catalytic activity and stability as it will be discussed in the following part of the present paper.

Moreover, considering that thermodynamic activity is an equilibrium parameter, care must be taken in order to insure that the exchanges of molecules between the different phases are in a steady state, and that a set of thermodynamic values dot not lead to the appearance of a liquid phase by modifying the global isotherm of the preparation, resulting in the definition of a solid/liquid/gas system. Some systems, reported as solid/gas systems were in fact solid/liquid/gas systems. ${ }^{34}$ 


\section{The possibility to determine intrinsic kinetic and activation thermodynamic parameters}

Liquid enzymatic reaction systems can be said to consist of three components : the substrate, the protein and the solvent. These three components interact and it is their overall interactions that determine the efficiency of the catalysis. The effects on catalysis and the differential activation parameters from each of these components are complex and highly interdependent. In the solid/gas enzymatic systems the addition of solvent is avoided and the microenvironment of the enzyme is solely composed of substrates and products molecules. It is therefore possible to measure enzyme activity in the absence of predominant species, contrary to liquid systems in which the solvent constitutes by far the most important molar fraction. The presence of such large quantities of solvent molecules in liquid media renders the interpretation of kinetic and thermodynamic measurements quite hazardous. Indeed, it is now well established that solvent molecules can directly interact with amino acids of the active site ${ }^{35,36}$. The result is an important effect of solvents on enzyme catalysis : numerous examples of modification of substrate specificity ${ }^{37}$, enantioselectivity ${ }^{38,39}$, thermodynamic and kinetic parameters ${ }^{40}$ can be found in the literature. Therefore the ability offered by the solid/gas technology of determining kinetic and thermodynamic parameters of an enzyme in the absence of solvent is fully interesting when looking for the own particular properties of an enzyme.

Moreover diffusion in the gaseous phase is more efficient than in solution because of very low viscosity coefficients and very high molecular diffusion coefficients values. Thus the reactions are less likely to be limited by diffusion.

For these reasons kinetic and thermodynamic parameters obtained in solid/gas reactors can be considered as "intrinsic parameters". 
To test the ability of the solid/gas system to determine intrinsic parameters of enzymes, we have performed a complete kinetic study of alcoholysis of methyl propionate and n-propanol catalysed by immobilised Candida antarctica lipase B in a continuous solid/gas reactor ${ }^{41}$. The kinetics obtained were suggested to fit a Ping Pong Bi Bi mechanism with dead-end inhibition by the alcohol (figure 7), as it is the case in liquid organic media and in supercritical carbon dioxide $^{42,43}$. Even if mechanism determination cannot rest on kinetic data alone, these result strongly suggest that the mechanism of lipase-catalysed alcoholysis is unchanged over a wide range of non conventional reaction media. The kinetic constants inherent to this model were calculated and the values obtained were compared with the ones obtained in liquid methyl-2 butanol-2. The use of thermodynamic activities to quantify substrate availability for the enzyme in both media permitted to express all kinetic constants in terms of thermodynamic activities and to compare them. This methodology permitted to point out a significant difference between results determined in the two media : values obtained for methyl propionate dissociation constant and propanol inhibition constant were found to be respectively 15 and 10 times lower in gaseous phase than the ones obtained in organic medium. Experimental studies are currently in progress to explain this difference; it already seems that the inhibition of the enzymatic activity afforded by solvent molecules could largely explain the apparent lower affinity of the enzyme for its substrates in liquid organic media. Indeed, several authors have explained part of the solvents effects on enzyme kinetics by competitive inhibition of the solvents ${ }^{28,44}$.

Concerning the determination of intrinsic enzymatic activation energies, the solid/gas system, which allows the measurement of activation energy of enzymatic reactions in absence of added solvent, appears also as an interesting tool. Indeed, the reaction thermodynamics are strongly influenced by substrate solvation and the ability of solvents to stabilize enzyme's transition state ${ }^{45,46}$. In an attempt to determine intrinsic effects of solvent polarity on subtilisin 
catalysis activation energies, Kim et al. $(2000)^{45}$ used a transfer free energy approach to calculate differences in activation energies between several organic solvents and acetone. The observed differences in activation energies were corrected for substrate desolvation, i.e. ground state stabilisation of substrate in a given solvent relative to acetone (the quantitative measure of this last effect was provided by saturation solubility experiments). This enabled "intrinsic enzymic activation energies" to be calculated, which resulted in a linear free energy relationship with respect to solvent polarity. This result was considered to be consistent with the charged nature of subtilisin's transition state. In this study, the calculation of differential activation energies required the choice of a particular solvent as a standard state (acetone in this case), despite the fact that it has its proper effect on substrate solvation and enzyme's transition state stabilisation. In this kind of investigation the solid/gas biocatalysis would afford an interesting standard state for enzymatic activation energy in the absence of solvent (provided that the substrate can be vaporised).

\section{A powerful tool for the determination of the role of water on biocatalysis}

The behaviour of biocatalysts in non-conventional media, is usually greatly affected by the level of water present in the medium. Numerous attempts have been made to investigate this dependence. As it is the case for the substrates, water availability in non-conventional media cannot be quantified using its concentration because the capacity of the medium to dissolve water varies considerably with its polarity. The influence of water is best analyzed in terms of its thermodynamic activity $\left(\mathrm{a}_{\mathrm{w}}\right)^{47,48}$.

Concerning the role of water on enzyme kinetics, as mentioned by many authors, the only way to assess the influence of water on enzyme kinetic behaviour is to perform a full kinetic description based on properly determined $k_{c a t}$ and $K_{M}$ values at different water activities ${ }^{49}$. 
Indeed it leads to the true maximal enzyme activity, and not substrate concentrationdependent activity.

If we focus on a particular class of enzymes, i.e. lipases, it appears that $\mathrm{k}_{\mathrm{cat}}$ obtained in liquid organic media generally increases with $\mathrm{a}_{\mathrm{w}}{ }^{50-52}$. This corresponds to the activation of enzyme by hydration, involving a general role of water in making the enzyme structure more flexible and mobile, increasing the turn-over rate. However high water levels have also been shown to reduce the rate of lipase-catalysed esterification or transesterification ${ }^{50,51}$. This decline cannot be attributed to water competition with the alcohol because $\mathrm{k}_{\mathrm{cat}}$ is obtained at a saturating substrate concentration, but might be due to physical aggregation of enzyme, reducing interfacial area and limiting mass transfer ${ }^{51,53}$. All these studies were performed in organic media, which makes the sole role of water impossible to assess. Indeed it was shown that at constant $\mathrm{a}_{\mathrm{w}}, \mathrm{k}_{\mathrm{cat}}$ varies with the organic solvent used. For example in the case of PEG-lipase catalysed transesterification $\mathrm{k}_{\mathrm{cat}}$ decreases with increasing solvent hydrophobicity ${ }^{51}$.

As far as the $K_{M}$ values are concerned, it is shown in several studies, that $K_{M}$ obtained at constant $\mathrm{a}_{\mathrm{w}}$ in different organic solvents vary with the solvent used, but as they are expressed in molar concentration instead of thermodynamic activity, it is impossible to distinguish between the variation ascribed to different partitioning of the substrate and water between the enzyme and the organic phase or to the influence of the solvent alone ${ }^{51}$. In an other study, $K_{M}$ obtained in different solvent were subjected to treatment with the UNIFAC group contribution method, to be expressed in thermodynamic activity, but this attempt failed to give adequate alignment of the $K_{M}$ in the different solvents ${ }^{52}$. This would indicate that solvent has a proper effect on this parameter.

As mentioned above the solid/gas process permits to limit the microenvironnement of the enzyme to substrates/products/water since no species are predominant, contrary to synthesis in organic solvent. As a consequence, the sole role of water can be better assessed. Moreover 
the thermodynamic activity of water can be continuously controlled by incorporating water in the inlet gas at the correct molar fraction.

We have studied the influence of water on the kinetics of alcoholysis of methyl propionate and $n$-propanol catalysed by immobilised lipase B from Candida antarctica in a continuous solid/gas reactor ${ }^{54}$. Results obtained concerning the substrate dissociation constants and propanol inhibition constants at different $\mathrm{a}_{\mathrm{w}}$ are summarised in table 2

It appears that water affects mainly the first step of the reaction, i.e. the acylation step, by first decreasing the dissociation constants between both enzyme and acyl substrate $\left(\mathrm{K}_{\mathrm{MP}}\right)$ and enzyme and alcohol $\left(\mathrm{K}_{\mathrm{I}}\right)$ when $\mathrm{a}_{\mathrm{W}}$ increases from 0 to 0.1 . This can be related to the general water-induced enzyme activation, observed when biocatalysis is performed in anhydrous medium ${ }^{35,55}$. From $a_{W}=0.1$ upwards water increases both $K_{I}$ and $K_{M P}$. It was suggested that water, as polar alcohols, binds to the enzyme through polar interactions and thereby blocks the access to the active site. These results suggest that addition of water in the solid/gas reactor mimicks an increase of solvent polarity in organic media. Indeed Garcia-Alles and Gotor $^{56}$ studied the kinetics of immobilised CALB-catalysed transesterification in nonaqueous organic media. They measured how the solvent affects the first substrate (ester) binding constant and the nucleophile inhibition constant. It was shown that these constants were significantly increased when the polarity of the solvent increased; these variations could not be explained using thermodynamic arguments (solvation of the ester or the inhibitor). The solvent itself could thus lead to a decrease of the affinity between enzyme and ester or nucleophile by an other effect than solvation of these molecules, like direct hindrance effect of the active site for example. It was shown that this effect increases with the polarity of the solvent. 
It appears in table 2 that $\mathrm{K}_{\mathrm{P}}$ is not influenced by $\mathrm{a}_{\mathrm{W}}$ nor by the state of the medium (gas or organic phase). This seems to mean that the second step of the reaction (deacylation) is not influenced by the microenvironment contrary to the first step (acylation step) which is both influenced by the water activity and the state of the medium.

As far the role of water on activation thermodynamic parameters is concerned, we have shown that the solid/gas technology afforded interesting results, again because of the possibility to perform catalysis in the absence of solvent.

We have determined the enthalpic and entropic contributions of water to the Gibbs free energy of activation the alcoholysis of methyl propionate and n-propanol catalysed by immobilised Candida antarctica lipase B both in a continuous solid/gas reactor and in an organic liquid medium (2-methyl-2-butanol $)^{57}$. It appears that $\Delta \mathrm{H}^{*}$ and $\Delta \mathrm{S}^{*}$ variations with $\mathrm{a}_{\mathrm{w}}$ are opposite in the two media. Upon increasing $\mathrm{a}_{\mathrm{w}}$, the effects involved in the gas phase was a decrease of the reaction energetic barrier $\left(\Delta \mathrm{H}^{*}\right)$ and an increase of enzyme flexibility $\left(\Delta \mathrm{S}^{*}\right)$, which means that the ground state ES complex occupies a broader distribution of conformational states. In the organic medium, the predominant phenomenon affecting thermodynamic parameters was an increased polarity of the solvent at high $a_{w}$, leading to an increase of the reaction energy of activation and to a decrease entropy level of the ground state ES complex.

Thus it appears that the influence of water on activation parameters measured in liquid media is a lot affected by the solvent itself. On the contrary the effects observed thanks to the solid/gas reactor can really be ascribed to water. 
Another component like an organic compound different from the reaction species can be added in the solid/gas biocatalysis system, by incorporating this additional species in the inlet gas. This offers the possibility to assess the role of this component at different chosen levels of availability

As an example, we have studied the effect of 2-methyl-2-butanol and hexane at a fixed thermodynamic activity of 0.3 , on kinetic parameters of the alcoholysis of methyl propionate by 1-propanol catalysed by immobilised lipase B from Candida antarctica ${ }^{58}$.

It has to be emphasized that this possibility to determine kinetic parameters at constant $\mathrm{a}_{2 \mathrm{M} 2 \mathrm{~B}}$ or ahexane by fixing the partial pressure of added 2-methyl-2-butanol or hexane in the carrier gas at the adequate value, and simultaneously varying $a_{M P}$ and $a_{P}$ to perform the full kinetic study, is a specific advantage of solid/gas reactors. As a comparison, we have calculated the variation of 2-methyl-2-butanol thermodynamic activity inherent to variations of substrate thermodynamic activities necessary to perform full kinetic study in liquid 2-methyl-2butanol as solvent : this involves variations of $\mathrm{a}_{2 \mathrm{M} 2 \mathrm{~B}}$ between 0.33 and 0.96 ! These $\mathrm{a}_{2 \mathrm{M} 2 \mathrm{~B}}$ values are obtained by calculations, from molar fractions using the UNIFAC group contribution method, and correspond for $\mathrm{a}_{2 \mathrm{M} 2 \mathrm{~B}}=0.33$ to the highest substrate quantities used $\left(\mathrm{a}_{\mathrm{P}}=0.5\right.$ and $\left.\mathrm{a}_{\mathrm{MP}}=0.3\right)$ and for $\mathrm{a}_{2 \mathrm{M} 2 \mathrm{~B}}=0.96$ to the lowest substrate quantities used $\left(\mathrm{a}_{\mathrm{P}}=0.01\right.$ and $\mathrm{a}_{\mathrm{MP}}=0.05$ ). This very important variation of $\mathrm{a}_{2 \mathrm{M} 2 \mathrm{~B}}$ makes the interpretation of solvent effect difficult and renders kinetic parameters obtained in liquid solvents questionable, when keeping in mind the proper effect of solvent on enzyme catalysis

Results obtained thanks to solid/gas technology concerning the effect of 2-methyl-2-butanol, hexane and water at $\mathrm{a}_{\mathrm{w}}=0.3$ on the inhibition constant of propanol are given in table 3 . It appears that inhibition by propanol is stronger $\left(\mathrm{K}_{\mathrm{I}}\right.$ lower) as the hydrophobicity of the added component increases $\left(\mathrm{K}_{\mathrm{I}}\right.$ hexane $<\mathrm{K}_{\mathrm{I}}$ 2-methyl-2-butanol $<\mathrm{K}_{\mathrm{I}}$ water $)$. These results indicate 
that these components interfere with the binding process between substrate and immobilized enzyme. As mentioned above these components, usually used as solvents in liquid media, would act as competitive inhibitor

In the solid/gas reactor, it is possible to study the effect of increasing thermodynamic activities of an added compound on enzyme activity, by keeping availability of substrates for the enzyme constant. This experiment is shown on figure 8 and clearly demonstrates the inhibitory character of water, 2-methyl-2-butanol and hexane. The more polar is the component, the more important is the inhibitory character. This has to be related to the effect of these components on the intrinsic value of $\mathrm{K}_{\mathrm{I}}$, indicating that the inhibition by propanol is stronger in the presence of hydrophobic component like hexane. It is thus clearly demonstrated that the effect of added organic component on alcoholysis catalyzed by lipase B from Candida antarctica is related to their inhibitory character. As reported by Uppenberg et $a l .{ }^{59}$, the region around the catalytic serine (Ser-105) is polar in nature so hydrophilic components may bind to this region to form a dead-end complex. This explains the differences of the $K_{I}$ intrinsic values obtained in presence of an apolar component like hexane, of a moderately polar tertiary alcohol such as 2-methyl-2-butanol and in presence of water.

\section{TECHNOLOGICAL APPLICATIONS OF SOLID/GAS BIOCATALYSIS}

\section{Enzyme technology: natural flavoring substances production.}

Esters represent an important class of aroma compounds. They often possess fruity odors and are widely used by the food and the fragrance industries. Many of interesting compounds are alkyl esters of acetic, propionic and butyric acids. Most of these compounds are obtained either by chemical synthesis for non-natural labeled molecules or by extraction 
from natural sources, dependent to seasonal, climatic and geographical variations and often require a large amount of raw materials.

A biotechnological process, can be an alternative solution for producing naturally labeled esters, minimizing then constraints encountered in natural extraction, and offering closer economical costs compared to the ones of the chemical processes.

Thanks to the thermodynamic approach we developed, quick optimization of solid/gas enzymatic catalysis to perform esterification reactions was achieved and direct esterification of natural kosher alcohols and acids by Novozym 435 has been transferred successfully to industrial scale for the production of fragrances and aromas ${ }^{60}$.

The methodology was constituted by different steps, all of them deriving from the determination of the $\Delta \mathrm{G}^{\circ}$ of the target reaction by determination of the $\mathrm{K}_{\mathrm{eq}}$ under different conditions in terms of thermodynamic activities of substrates and water. For all syntheses, three different inlet conditions were applied for obtaining the correct value of $\Delta \mathrm{G}^{\circ}$.

Once the $\Delta \mathrm{G}^{\circ}$ was obtained, in silicon optimization was realized, after experimental determination of thermodynamic barriers. These barriers were defined by kinetic experiments, and stability tests and corresponded to the upper limits of thermodynamic activities for alcohols, acids or water affecting either the stability or the reaction rate of the catalyst. Cross effects (especially concerning water and acid moieties) were also studied.

Taking into account these barriers, further optimization was realized taking into account the process constraints (liquid and gaseous flows, power consumption, absolute pressure on the different stages)

Tests using the defined set of parameters were then performed at the lab scale for samples production at the kilogram level. This last step also permitted to validate the stability 
of the catalyst over periods varying from 50 to 100 hours. Then, results were directly transferred at the pilot scale for validation.

The industrial pilot used for real production tests is depicted on figure 9. This setup is developed on a closed loop of nitrogen, circulating in three different zones, thus reducing the nitrogen consumption to zero during continuous operation.

This loop is realized between a low pressure zone (flashing unit, heat exchanger and bioreactor), a medium pressure zone (gas/liquid separator) and a high pressure zone (final condenser) .

Liquid substrates (acid and alcohol), water and nitrogen are injected into a flashing unit using a pressurized loop with a mass controlled leak going to the flashing unit of each flow for liquid substrates. Once the liquid/gas flash is realized in the flashing unit, the gas enters in a heat exchanger and its outlet temperature is set to the working temperature of the bioreactor. Then, the thermodynamic activities in the gaseous stream are obtained at this stage by controlling each partial pressure as explained previously. A packed bed type reactor follows the heat exchanger, and all this part of the system is maintained under regulated vacuum using the liquid ring vacuum pump and the vacuum regulation valve. After catalysis, the end of the process is solely dedicated to the removal of condensable molecules from the nitrogen fraction, and is performed by a two stages condensation operation involving a cooling of the gas stream coupled to an increase of absolute pressure performed by the liquid ring vacuum pump itself and a compressor for finishing the condensation process. Then, clean nitrogen at the outlet of the pressurized heat exchanger can be depressurized and recycled to the flashing unit.

In order to control proper operation of the installation, an automated sampling system was developed for gas chromatograph analyses. Thus, recycled nitrogen, inlet and outlet gaseous 
streams on the bioreactor were sampled and analyzed for on line monitoring purposes. Complete automated supervision was developed, in order to define a process able to operate without any human supervision. Figure 10 gives an overview of the overall plant.

Fig 11 shows an example of butyric alkyl ester synthesis realized at a productivity level of $2.5 \mathrm{~kg} /$ hour of ester. Because the esterification reaction is exergonic $\left(\Delta \mathrm{G}^{\circ}\right.$ varying from -14 to $-9,5 \mathrm{~kJ} / \mathrm{mole}$ for the different syntheses), the removal of heat produced during the reaction over the packed bed on the pilot installation was found to be insufficient.

As a result, it exists a gradient of temperature over the catalytic bed, function of the degree of conversion and total molar flow passing over the bed. Thus, temperature at the outlet of the reactor was found to be higher of 15 to $20^{\circ} \mathrm{C}$ in the majority of the tests performed at productivity levels of 3 to $5 \mathrm{~kg}$ of ester per hour.

As shown in the example of fig 11 , since the inlet temperature was $80^{\circ} \mathrm{C}$ and the productivity was set at $2.5 \mathrm{~kg} / \mathrm{hr}$ of ester, the temperature of the gas at the outlet was under steady state stabilized around $89^{\circ} \mathrm{C}$. The main effect of this variation of temperature on the catalytic bed was a slight decrease of the maximal conversion of the acidic moiety of $1.5 \%$ as shown on the measured conversion. Since no rapid denaturation of the catalyst was observed by a rapid decrease of the acidic conversion, heat produced by the catalysis was found to be responsible of the decrease of the conversion observed during the first hours. Calculation of the theoretical equilibrium point at $89^{\circ} \mathrm{C}$ gave the same value as the one that was measured during the experiment indicating thus that the temperature of the catalyst was in equilibrium with the gas leaving the bioreactor and that the increase of temperature was solely responsible of the lower conversion achieved, by changing the thermodynamic activities of the different chemical species, thus modifying the composition of the gas at the equilibrium. Stability was checked for the different syntheses taking into account the heat exchange over the catalytic 
bed. The half-life time of the reactors for the different synthesis was found to vary from 850 to more than 2000 hours for outlet temperatures ranging from 90 to $120^{\circ} \mathrm{C}$. More detailed analysis of the behavior of the catalytic bed strengthens the conclusion that stability in this system is mainly governed by the acid thermodynamic activity. As a result, the reactor is not homogeneous in terms of stability and the catalyst is more subject to denaturation in its first part (lower temperature, higher acid thermodynamic activity) than in the last part (higher temperature, lower acidic thermodynamic activity). Different syntheses coupling $\mathrm{C} 1$ to $\mathrm{C} 4$ carboxylic acids and $\mathrm{C} 1$ to $\mathrm{C} 9$ alcohols for the industrial production of natural aromas were optimized and tests production were performed. Table 4 summarizes some examples of the productivity that the system can achieve with an acidic conversion higher than $95 \%$ and a maximal excess of alcohol of 2 (mole per mole) in the worst cases $\left(\Delta \mathrm{G}^{\circ}>-11 \mathrm{~kJ} / \mathrm{mole}\right.$ ) for residence time commonly observed as low as 0.5 to 0.15 second.

If the production of natural esters is the first example of a large scale application of solid/gas biocatalysis, many other systems are studied today in the view of short or medium term development.

Lipases, offer an important potential of applications since they are able to carry out reactions of esterification as well as transesterification (acidolysis or alcoholysis), inter esterification or hydrolysis. Moreover, their specificity and/or selectivity is suitable for the production of high added value molecules (stereospecific alkylation, acylation or hydrolysis for the resolution of racemic mixtures of acids, alcohols or esters).

Dehydrogenases also represents a class of interesting enzymes since chiral reduction of ketones can lead to the production of enantiomerically pure alcohols for the fine chemistry, and since it was demonstrated that the regeneration of the cofactor was effective in a solid/gas system by addition of a second substrate ${ }^{3}$. 
Many other applications can be envisaged, but one must take into account that solid/gas biocatalysis can only be applied to transformations involving compounds presenting a criteria of volatility, thus limiting the fields of applications to smaller molecules, compared to the ones accessible by other systems (liquid or supercritical ones)

\section{The next challenge: using whole cells.}

Solid/gas biocatalysis must not remain only synonymous of use of isolated and purified enzymes. Whole cells are of particular interest, on one hand by the lowering of the costs related to the catalyst compared to the use of purified enzymes, and on the other hand by the possibility of coupling several enzymatic systems in cascade in a same micro reactor constituted by the cell itself. One of the major application that should get benefit of the technology has a strong environmental impact and concerns applications related to the bioremediation of gas effluents.

Different strategies can be envisaged for the bioremediation of polluted gases and two main approaches can be defined:

- either a simple modification of the pollutant for facilitating its trapping in a second step (reduction of aldehydes or ketones to produce the corresponding alcohols presenting a lower volatility, dehalogenation of chloro alkanes, leading to the formation of epoxides or alcohols, acylation or alkylation for increasing the chain length or modifying the hydrophilic/hydrophobic balance...),

- or performing a cascade of reactions insuring a catabolic degradation of the pollutant. 
Although some work was initiated at the end of the 80 's on the subject, no real development has outcome of the reported works. Nevertheless, some works were recently published in the scope of providing new solutions for bioremediation purposes.

Alcohol dehydrogenases are of particular interest since they are able to catalyze reactions of oxido-reduction with different specificities according to their origin towards primary or secondary alcohols. Nevertheless, they present a major disadvantage which is the use of a relatively expensive nicotinamidic cofactor.

Thus the use of whole cells used as an enzymatic bag containing enzymes and cofactor has received many attention over the past decades in liquid systems in order to develop processes insuring an efficient in situ cofactor regeneration.

However, the majority of the systems were confronted with the washing of the cofactor by the liquid phase. Solid/gas catalysis can constitute an interesting alternative for solving this problem, since the washing of the cofactor by a circulating gas is impossible because of its non volatile character.

Maugard et $a l,{ }^{61}$ showed that the reduction of an aldehyde to the corresponding primary alcohol by Saccharomyces cerevisiae lyophilized cells, was possible in a solid/gas system with an effective cofactor regeneration insured by the oxidation of ethanol.

However, this work and results published by Goubet ${ }^{15}$ highlighted an important effect of the cellular matrix, which modifies completely the conditions of hydration necessary to the expression of the catalytic activity.

Haloalkane dehalogenase is an enzyme capable of catalyzing the conversion of shortchained aliphatic halogenated hydrocarbons to a corresponding alcohol. Because of its broad 
substrate specificity and cofactor independence, haloalkane dehalogenases are attractive biocatalysts for gas-phase bioremediation of pollutant halogenated vapor emissions.

Work recently published on haloalkane dehalogenase activity from Rodococcus erythropolis cells for the hydrolysis of chloro and bromo alkanes also highlighted the importance of the cellular matrix constituting the macro environment of the enzyme. ${ }^{16}$ Since higher water activity is required for revealing the activity in whole cells compared to the necessary one for the purified enzyme, the authors showed that proton exchange was effective in the system, due to the production of $\mathrm{HCl}$ after hydrolysis of chloro alkanes. Addition of a volatile Lewis base (triethylamine), coupled to treatment of cell wall by lysozyme showed that inhibition by $\mathrm{HCl}$ could be prevented efficiently. Some similar results were reported previously concerning the use of purified haloalkane dehalogenase from Rhodococcus rhodochrous concerning the dehalogenation reaction of 1-chlorobutane or 1,3dichloropropane by Dravis et al. ${ }^{62}$ Nevertheless, the Rhodococcus rhodochrous dehalogenase was found to require a water activity of 1 . (A water activity of 0.5 led to a decrease of $80 \%$ in enzymatic activity). Triethylamine addition, altering the electrostatic environment of the enzyme via a basic shift in local $\mathrm{pH}$, allowed under such conditions of hydration a tenfold increase in activity.

Whole cells appear as suitable catalysts for solid/gas biocatalysis. Nevertheless, while the technological feasibility has been demonstrated, the optimization of these systems involving cells remains a hard task. Some routes are identified, and a better comprehension of the effects due to macro and micro-environment of the enzyme and the factors affecting the hydration/solvation of the catalytic material clearly constitutes the key for maintaining these systems active and stable for proper operation. 
Concerning the realization of cascade of reactions, no consistent data are available in the literature, proving that multiple steps reactions can take place in the same cell.

Some work reported by Barzana ${ }^{6}$ showed that two enzymatic systems were able to be active at the same time. The oxidation of primary alcohol by cells of Pischia pastoris involving an alcohol oxidase can be enhanced in term of stability by the addition of catalase or peroxidase, by elimination of the activated species of oxygen produced during the reaction. But these two enzymatic systems are not both located in the cell.

Following the work reported by $\mathrm{Hou}^{23}$, concerning the methane monooxygenase from Methylosinus sp CRL 31 for the production of epoxides, we tested the degradation of trichloroethylene by freeze-dried cells of Methylosinus trichosporium (unpublished results). According to the degradation pathway presented on figure 12 , the unique action of the methane monooxygenase results in 3 possible products: the epoxyde, the dichloroacetate or the chloral hydrate.

Further degradation requires the action of dehydrogenases or others monooxygenases in cascade to degrade trichloroethylene either in metabolic intermediates, or in $\mathrm{CO}_{2}$ and $\mathrm{HCl}$ in the case of a complete degradation. The residual concentration of TCE measured at the outlet of the reactor over a period of 24 hours showed that freeze-dried cells of $M$. trichosporium were able to degrade all the TCE in a continuous way. The presence of any product of the action of methane monooxygenase (epoxide, chloral hydrate or dichloroacetate) was not detected in the outlet gas, suggesting a possible re-use by a second (or several) enzymatic system(s) since all the three products have a sufficient saturation vapor pressure at $40^{\circ} \mathrm{C}$ for being removed continuously by the gaseous stream.

Then cascade of reaction may occur in whole cells, but the complete characterization of the different tested systems still has to be done, and more fundamentals studies appear necessary if one wants to ensure the development of new efficient biofilters. 


\section{CONCLUSION}

Solid/gas system appears as a powerful tool for studies devoted to the effect of hydration/solvation and more generally for studies on the effect of modification of the microenvironment on biocatalytic ativity and stability. The main reason is that solid/gas systems allow a very accurate control of the microenvironment of the biocatalyst by a complete independent control of thermodynamic parameters.

Nevertheless, a lot of questions are still without clear answer, and numerous work still remains to be done in order to make the following clearer :

- does the biocatalysis occur directly with molecules in the gaseous state or does the biocatalysis necessitate first a kind of solvation of the enzyme by its substrates?

- What are the energetics in solid/gas biocatalysis compared to liquid systems?

- How do the mechanisms of enzymes working on gaseous substrates differ from those in solution and especially concerning the binding step and the catalytic process?

- What is the exact influence of water and organic molecules on the enzyme structure ? Could it be predictable to act on properties such as selectivity, affinity, binding constants and catalytic constants by controlling the hydration/solvation state?

- What can be the partition of water and organics on more complicated systems such as whole cells, and how the physico-chemical properties of the macro and micro environments can affect this distribution?

But, solid/gas biocatalysis, because of its peculiarities enables a more accurate approach for studying the effect of the microenvironment on enzymatic activity and stability. This allows to have an access to intrinsic parameters, thus providing additional information for a molecular understanding of enzyme catalysis in general. Finally, solid/gas catalysis appears 
probably as the most appropriate and the most complementary experimental tool for validating molecular modelization experiments.

From a more applied point of view, biocatalysis in the gas phase seems today more promising than ten years ago, since the demonstration of its ability to face new biotechnological processes, not only in terms of technical feasibility but also in terms of productivity and competitiveness has been successfully performed.

Nevertheless, important bottlenecks still exist, and the next challenge will really be the use of whole cells as micro reactors for multi steps transformations and the development of technological tricks allowing to enlarge the number of compounds that shall be usable by the technology.

Moreover, solid/gas technology represents a clean technology, since, compared to the organic liquid systems, the use of organic solvent can be reduced to zero. Its use shall lead to the definition of "green processes" and numerous applications should get benefit of this technology concerning either the production of biomolecules or the bio-treatment of waste gases for toxic removal or modification.

Beside these application fields, biosensors and analytical techniques should beneficiate from the technology. Some examples have already been described concerning the use of a biological part constituting the body of detection, and a transmitter for detection in gaseous media $^{34}$. The detection of formaldehyde by a formaldehyde dehydrogenase coated onto a piezoelectric crystal was performed at the ppm level. Detection of pesticides and organophosphorous compounds at the level of ppb has been rendered possible by the same technique involving either acetylcholinesterase or butyrylcholinesterase. And lastly, very 
specific biosensors were developed with the same approach by using antibodies directed against parathion, or against the benzoyl ecognine for the specific detection of cocaine.

Concerning analytical developments, one can imagine easily that affinity gas chromatography can be envisaged seriously, as well as the realization of on-line specific derivatization precolumns for $\mathrm{GC}$ analysis. 


\section{REFERENCES}

2

3

E. Barzana, A. Klibanov, and M. Karel, Appl. Biochem. Biotechnol. 15, 25-34. (1987)

6

E. Barzana, A. Klibanov, and M. Karel, Biotechnology And Bioengineering 34, 1178 1185. (1989).

7 (1992).

H. Uchiyama, K. Oguri, O. Yagi, and E. Kokufuta, Biotechnology Letters 14, 619622. (1992) 
M. Zilli, A. Converti, A. Lodi, M. Del Borghi, and G. Ferraiolo, Biotechnology And Bioengineering 41, 693-699. (1992)

I. Goubet, T. Maugard, S. Lamare, and M. D. Legoy, Enzyme and Microbial Technology 31, 425-430 (2002).

B. Erable, T. Maugard, I. Goubet, S. Lamare, and M. D. Legoy, Process Biochemistry In Press, Corrected Proof (2004).

J. B. A. Vantol, R. M. M. Stevens, W. J. Veldhuizen, J. A. Jongejan, and J. A. Duine, Biotechnology and Bioengineering 47, 71-81 (1995). 
A. E. M. Janssen, A. M. Vaidya, and P. J. Halling, Enzyme Microbiol. Technol. 18, 340-346 (1996).

A. E. M. Janssen, B. J. Sjursnes, A. V. Vakurov, and P. J. Halling, Enzyme and Microbial Technology 24, 463-470 (1999).

P. Halling, Enzyme and Microbial Technology 16, 178-206 (1994).

P.-H. Yang and J. Rupley, Biochemistry 18, 2654-2661 (1979).

B. Hahn-Hagerdäl, Enzyme and Microbial Technology 8, 322-327. (1986).

S. Lamare and M. D. Legoy, Trends In Biotechnology 11, 413-418 (1993).

P. P. Wangikar, T. P. Graycar, D. A. Estell, D. S. Clark, and J. S. Dordick, J. Amer. Chem. Soc. 115 (1993).

J. L. Schmitke, L. J. Stern, and A. M. Klibanov, Proc. Natl. Acad. Sci. USA 95, 12918-12923 (1998).
C. R. Wescott and A. M. Klibanov, J. Amer. Chem. Soc. 115, 1629-1631 (1993).

P. A. Fitzpatrick and A. M. Klibanov, J. Amer. Chem. Soc. 113, 3166-3171 (1991).

J. Ottosson, L. Fransson, J. W. King, and K. Hult, Biochimica et Biophysica Acta (BBA) - Protein Structure and Molecular Enzymology 1594, 325-334 (2002).

J. B. A. Van Tol, J. A. Jongejan, J. A. Duine, H. G. T. Kierkels, E. F. T. Gelade, F. Mosterd, W. J. J. van der Tweel, and J. Kamphuis, Biotechnology and Bioengineering 48, 179-189 (1995).

M. P. Bousquet-Dubouch, M. Graber, N. Sousa, S. Lamare, and M. D. Legoy, Biochimica Et Biophysica Acta-Protein Structure and Molecular Enzymology 1550, 90-99 (2001).

W. Chulalaksananukul, J. S. Condoret, P. Delorme, and R. M. Willemot, FEBS Letters 276, 181-184 (1990). 
A. Marty, W. Chulalaksananukul, R. M. Willemot, and J. S. Condoret, Biotechnology and Bioengineering 39, 273-280 (1992). M. Martinelle and K. Hult, Biochimica et Biophysica Acta (BBA) - Protein Structure and Molecular Enzymology 1251, 191-197 (1995).

J. Kim, D. S. Clark, and J. S. Dordick, Biotechnology and Bioengineering 67, 112-116 $(2000)$

C. R. Wescott and A. M. Klibanov, Biotechnology and Bioengineering 56, 340-344 (1997)

J. M. Cassells and P. J. Halling, Enzyme and Microbial Technology 10, 486-491 (1988)

P. J. Halling, in Biocatalysis in organic media, edited by C. Laane, J. Tramper, and M. D. Lilly (Elsevier, Amsterdam, 1987), p. 125-132.

R. H. Valivety, P. J. Halling, and A. R. Macrae, Biotechnology Letters 15, 1133-1138 $(1993)$

R. Bovara, G. Carrea, G. Ottolina, and S. Riva, Biotechnology Letters 15, 937-942 $(1993)$

E. Wehtje and P. Adlercreutz, Biotechnology and Bioengineering 55, 798-806 (1997).

R. H. Valivety, P. J. Halling, and A. R. Macrae, Biochimica et Biophysica Acta (BBA)

- Protein Structure and Molecular Enzymology 1118, 218-222 (1992).

M. Graber, M. P. Bousquet-Dubouch, S. Lamare, and M. D. Legoy, Biochimica Et Biophysica Acta-Proteins and Proteomics 1648, 24-32 (2003).

J. L. Schmitke, C. R. Wescott, and A. M. Klibanov, J. Amer. Chem. Soc. 118, 33603365 (1996). 
L. F. Garcia-Alles and V. Gotor, Biotechnology and Bioengineering 59, 684-694 (1998)

M. Graber, M. P. Bousquet-Dubouch, N. Sousa, S. Lamare, and M. D. Legoy, Biochimica Et Biophysica Acta-Proteins and Proteomics 1645, 56-62 (2003).

F. Letisse, S. Lamare, M.-D. Legoy, and M. Graber, Biochimica et Biophysica Acta (BBA) - Proteins \& Proteomics 1652, 27-34 (2003)

J. Uppenberg, N. Ohrner, M. Norin, K. Hult, G. J. Kleywegt, S. Patkart, V. Waagen, T. Anthonsen, and T. A. Jones, Biochemistry 34, 16838-16851 (1995).

60

S. Lamare, B. Caillaud, R. Karine, I. Goubet, and M. D. Legoy, Biocatalysis and Biotransformation 19, 361-377 (2001).

T. Maugard, S. Lamare, and M. D. Legoy, Biotechnology And Bioengineering 73, $164-168(2001)$

62

B. C. Dravis, P. E. Swanson, and A. J. Russell, Biotechnology And Bioengineering 75, 416-423 (2001). 
Table 1: Compositions and characteristics of two gases for the same reaction in terms of thermodynamic activity performed at two different absolute pressures.

\begin{tabular}{|l|c|c|}
\hline \multicolumn{1}{|c|}{ Absolute working pressure (atm) } & $\mathbf{1 . 0}$ & $\mathbf{0 . 2}$ \\
\hline Minimal flashing temperature required $\left({ }^{\circ} \mathrm{C}\right)$ & 200 & 100 \\
Reactor inlet : $\mathrm{Pp}_{\mathrm{X}} / \mathrm{Pp}_{\mathrm{H} 20} / \mathrm{Pp}_{\mathrm{N} 2}$ & $0.02 / 0.10 / 0.88$ & $0.02 / 0.10 / 0.08$ \\
Reactor inlet : $\mathrm{Q} \times \mathrm{X} / \mathrm{Q}_{\mathrm{H} 20} / \mathrm{Q}_{\mathrm{N} 2}(\mathrm{~mol} / \mathrm{h})$ & $2 / 10 / 88$ & $10 / 50 / 40$ \\
Productivity : $\mathrm{Q}_{\mathrm{Y}}(\mathrm{mol} / \mathrm{h})$ & 2 & 10 \\
Organic charge of the gas ( molar \%) & $12 \%$ & $60 \%$ \\
Ppy at the outlet : (atm) & 0,02 & 0,02 \\
Pp at the inlet of the condenser : (atm) & 0,02 & 0.1 \\
Condensation efficiency (\%) & 50 & 90 \\
Productivity after condensation (mole/h) & 1 & 9 \\
Loss of $\mathrm{Y}$ after condensation step (\%) & 50 & 10 \\
\hline
\end{tabular}

Table 2 : Effect of $\mathrm{a}_{\mathrm{w}}$ on dissociation constants of propanol-enzyme, enzyme-methyl propionate and acyl-enzyme-propanol complexes respectively $\left(\mathrm{K}_{\mathrm{I}}, \mathrm{K}_{\mathrm{MP}}\right.$ and $\left.\mathrm{K}_{\mathrm{P}}\right)$

\begin{tabular}{|l|c|c|c|c|}
\cline { 2 - 5 } \multicolumn{1}{c|}{} & \multicolumn{1}{|l|}{$\mathrm{a}_{\mathrm{W}}$} & \multicolumn{1}{l|}{$\mathrm{K}_{\mathrm{I}}$} & $\mathrm{K}_{\mathrm{MP}}$ & $\mathrm{K}_{\mathrm{P}}$ \\
\hline \multirow{3}{*}{ Gas phase } & 0 & 0.019 & 0.047 & 0.022 \\
\cline { 2 - 5 } & 0.1 & 0.009 & 0.009 & 0.015 \\
\cline { 2 - 5 } & 0.2 & 0.052 & 0.044 & 0.021 \\
\cline { 2 - 5 } & 0.3 & 0.161 & 0.161 & 0.013 \\
\hline Organic phase $^{*}$ & 0 & 0.160 & 0.651 & 0.020 \\
\hline
\end{tabular}

* results from Bousquet-Dubouch et al. ${ }^{41}$ 
Table 3 : Effect of water, 2-methyl-2-butanol and hexane on dissociation constants of propanol-enzyme complex $\left(\mathrm{K}_{\mathrm{I}}\right)$ in the solid/gas reactor

\begin{tabular}{|c|c|c|}
\hline Added component & $\begin{array}{c}\text { Thermodynamic } \\
\text { activity }\end{array}$ & $\mathrm{K}_{\mathrm{I}}$ \\
\hline None & 0 & $0.019^{*}$ \\
\hline Water & 0.3 & $0.161^{* *}$ \\
\hline 2-methyl-2-butanol & 0.3 & 0.045 \\
\hline Hexane & 0.3 & 0.018 \\
\hline
\end{tabular}

* results from Bousquet-Dubouch et al. (2001) $)^{41}$

** results from Graber et al. $(2003)^{54}$

$\underline{\text { Table } 4}$ : Examples of ester productivity and acid conversion achieved on the preindustrial scale bioreactor for different optimized syntheses of acetic, propionic, butyric or iso-butyric acid alkyl esters.

\begin{tabular}{c|c|c|c|c} 
Acidic Moiety & $\begin{array}{c}\text { Number of } \\
\text { alcohols tested }\end{array}$ & $\begin{array}{c}\text { Acid conversion } \\
\text { (\%) }\end{array}$ & $\begin{array}{c}\text { Ester } \\
\text { Productivity } \\
\mathbf{( k g / h )}\end{array}$ & $\begin{array}{c}\text { Catalyst } \\
\text { Charge } \\
\mathbf{( k g )}\end{array}$ \\
\hline Formic & 2 & $94.0-95.4$ & $1.5-2.0$ & $2.0-3.0$ \\
Acetic & 5 & $95.0-97.4$ & $3.8-4.0$ & $2.0-3.0$ \\
Propionic & 5 & $95.6-98.0$ & $3.0-4.5$ & $2.0-3.0$ \\
Butyric & 5 & $97.5-98.1$ & $2.6-3.2$ & 2.0 \\
Iso-Butyric & 5 & $94.0-97.8$ & $2.2-3.5$ & 2.0
\end{tabular}




\section{DIAGRAM LEGENDS}

Figure 1: schematic diagram of solid gas catalysis in a packed bed reactor.

Figure 2: example of partial pressure saturation curves (VLE equilibriums).

Figure 3: from Lamare and Legoy, (1995)

schematic diagram of a packed bed solid gas bioreactor working at atmospheric pressure.

Figure 4: from Lamare and Legoy, (1999) ${ }^{10}$

schematic diagram of a packed bed solid gas bioreactor working at reduced pressure.

Figure 5: from Yang P.-H. and Ruppley A. (1979) ${ }^{32}$

Variation of lysozyme specific heat as a function of its hydration state.

Figure 6: from Drapron R. $(1985)^{20}$

Schematic diagram of an isotherm sorption curve.

Figure 7: from Bousquet-Dubouch et al. $(2001)^{41}$

Reciprocal initial rates versus reciprocal $a_{M P}$ for different $a_{P}$ values.

Synthesis was carried out in the solid/gas bioreactor at $70^{\circ} \mathrm{C}$, at a molar flow of $1 \mathrm{mmol} \cdot \mathrm{min}^{-1}$ in the presence of $15 \mathrm{mg}$ of adsorbed CALB onto Chromosorb AW DMCS. Water activity was set near to 0 .

For low $a_{P}$ values (from 0.007 to 0.016 ), the plotted profiles were parallel with a decrease of the $1 / \mathrm{V}$ axis intercept. For higher a values, the plots converged to a limit of $1 / \mathrm{Vmax}$ on the $y-$ axis corresponding to $1 / \mathrm{a}_{\mathrm{MP}}$ equal to 1 . Indeed, in the present case, as thermodynamic activities are used instead of classical concentrations, the $1 / \mathrm{Vmax}$ axis is not the usual $y$-axis (for $1 / a_{M P}$ values equal to zero) but a parallel axis corresponding to $1 / a_{M P}$ values of 1 , corresponding to the highest possible value of $\mathrm{a}_{\mathrm{MP}}$. These results agree with the Ping Pong Bi Bi mechanism with dead-end inhibition by the alcohol. 
Figure 8: from Létisse et al. $(2003)^{58}$

Effect of water, hexane and 2-methyl-2-butanol thermodynamic activity on initial rates.

Reaction was carried out at $70^{\circ} \mathrm{C}$, at a molar flow of $1 \mathrm{mmol} \cdot \mathrm{min}^{-1}$ in the presence of $15 \mathrm{mg}$ of adsorbed CALB onto Chromosorb AW DMCS. Methyl propionate and propanol thermodynamic activities were fixed at 0.15 and thermodynamic activity of solvents was varied from 0 to 0.6 .

Figure 9: Schematic diagram of the industrial continuous solid/gas bioreactor.

Figure 10: Industrial solid/gas bioreactor.

Figure 11: Production run of a butyric acid alkyl ester realized at $80^{\circ} \mathrm{C}$ (inlet gas temperature). The productivity was set at $2.5 \mathrm{~kg}$ of ester per hour.

Figure 12: TCE removal in solid/gas bioreactor by $M$. trichosporium freeze-dried cells. 50mg of dehydrated cells are placed in a packed bed reactor at $40^{\circ} \mathrm{C}$. Inlet gas contains water, TCE and methanol at the following levels : $\mathrm{a}_{\mathrm{w}}=0.7, \mathrm{a}_{\mathrm{TCE}}=0.1, \mathrm{a}_{\text {méthanol }}=0.1$. The total gaseous flow is set at $500 \mu$ moles $\min ^{-1}$. 


\section{FIGURE 1}

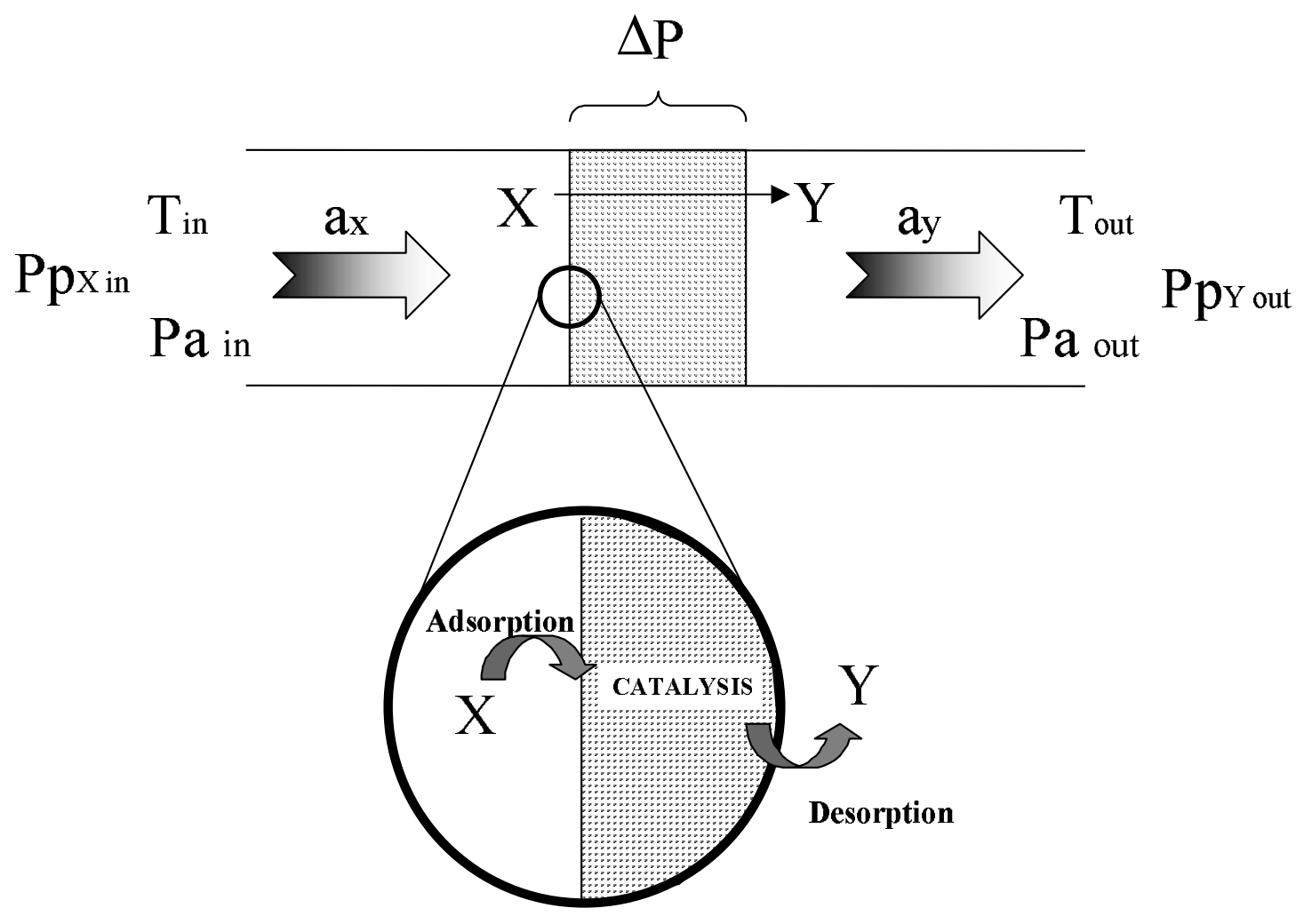


FIGURE 2

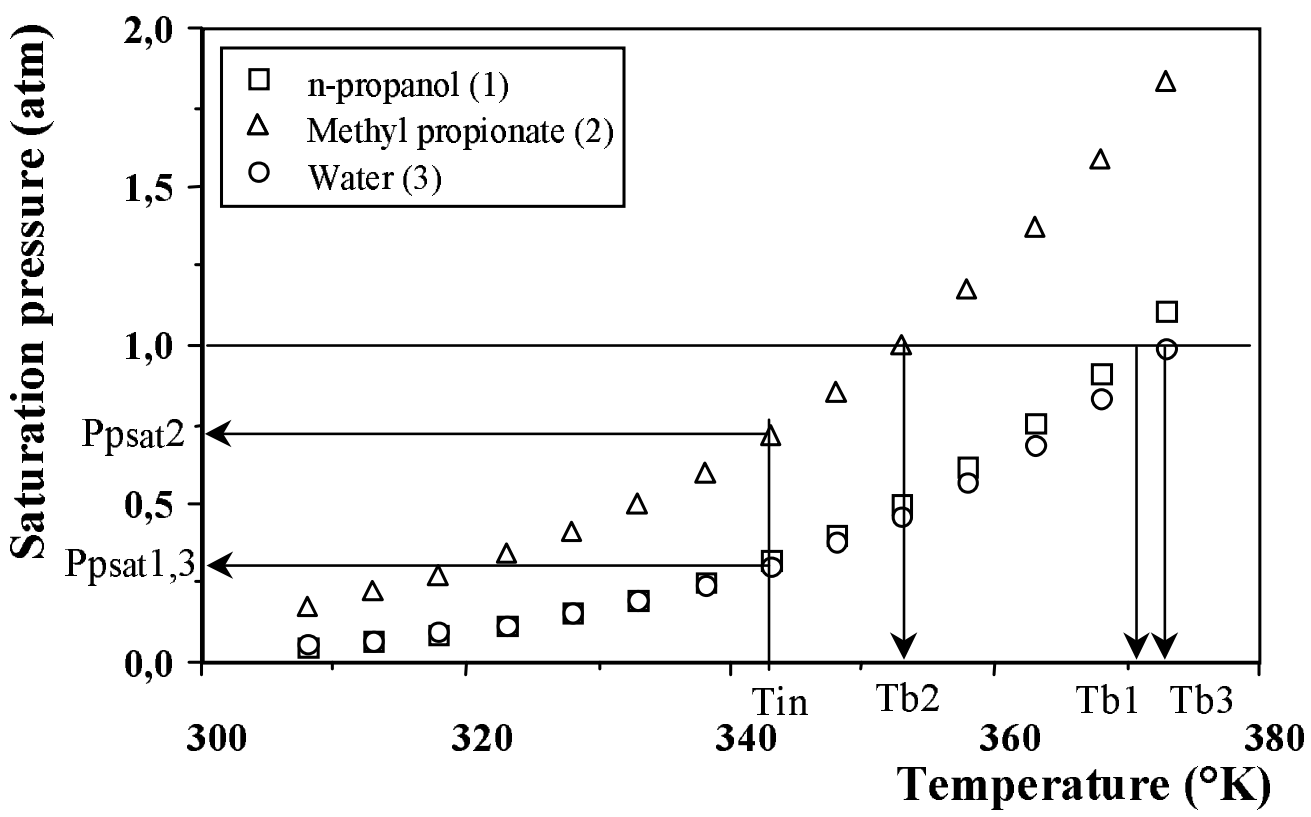


FIGURE 3

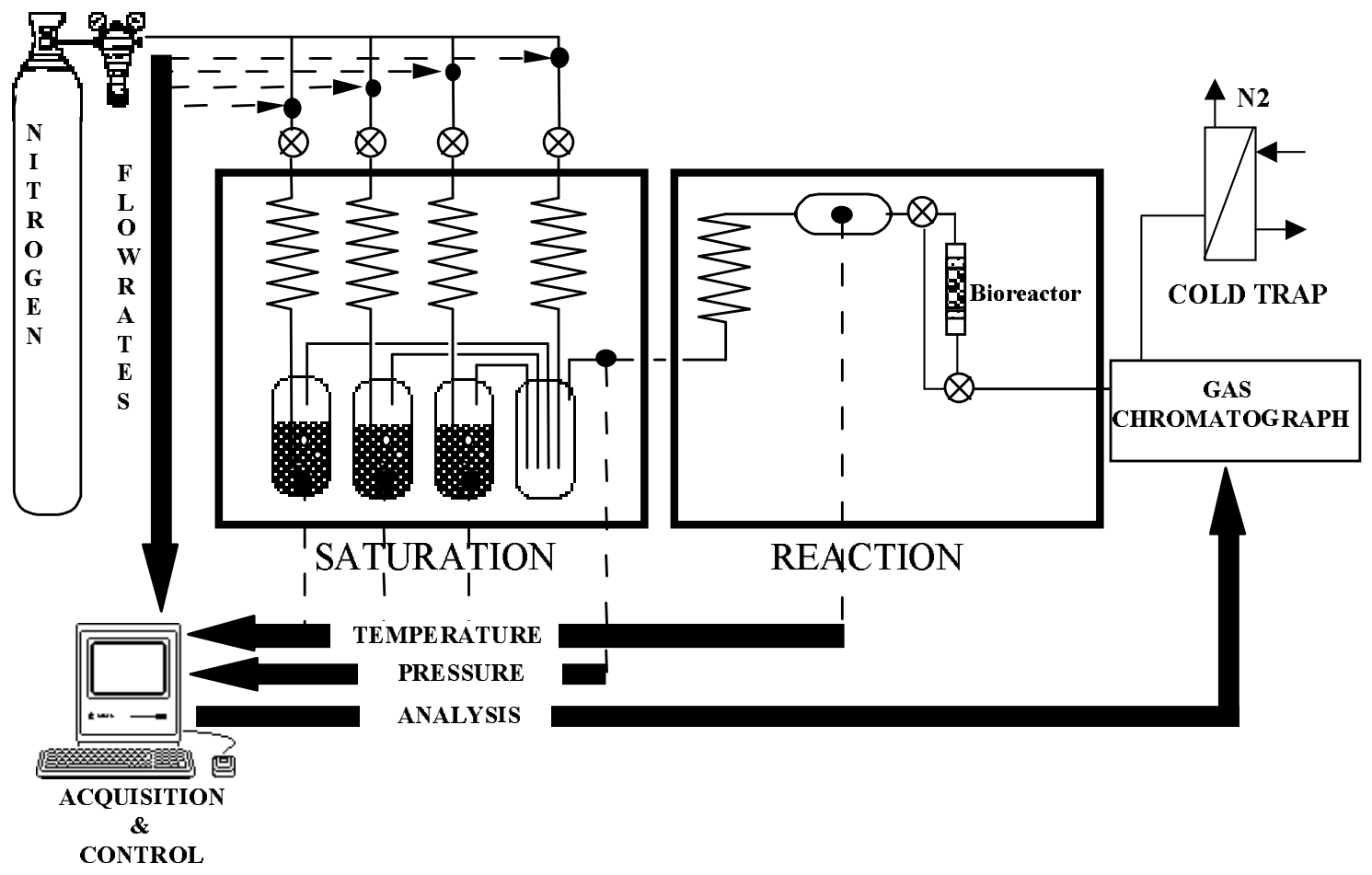


FIGURE 4

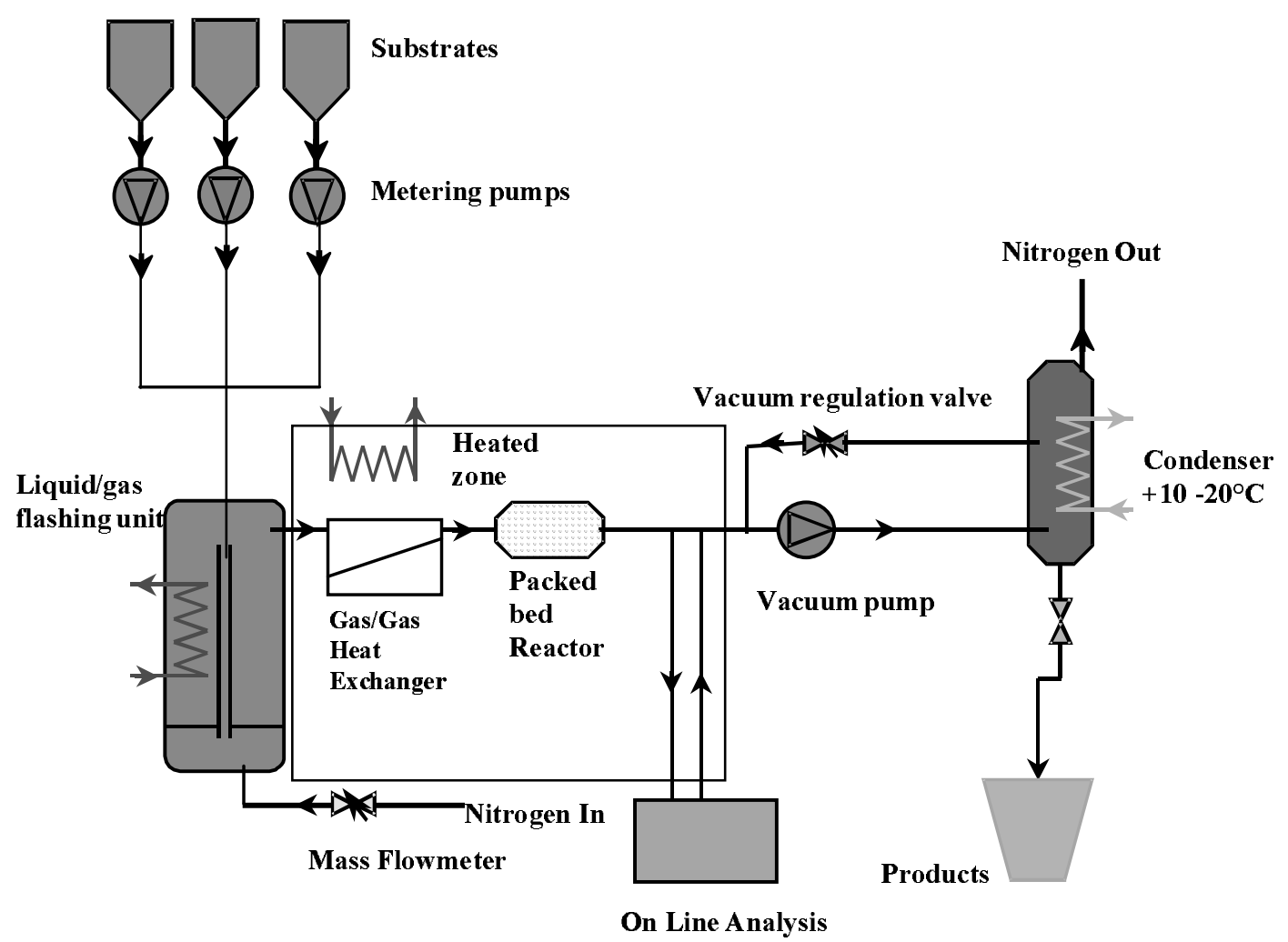


FIGURE 5

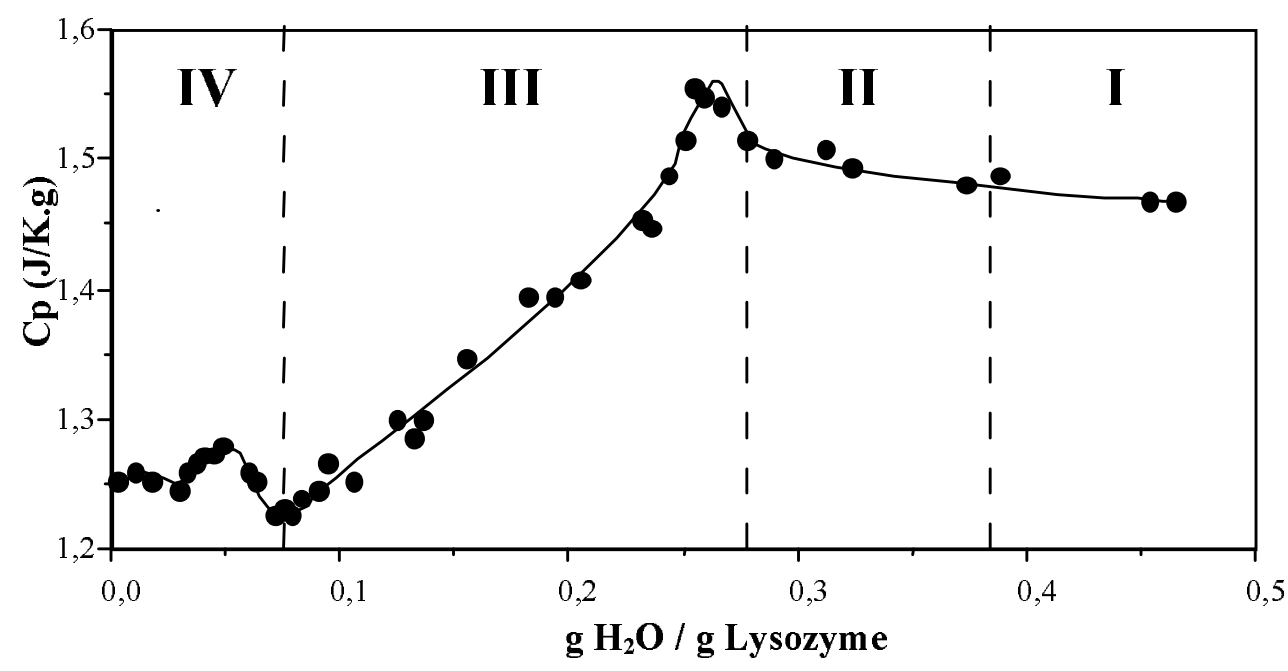


FIGURE 6

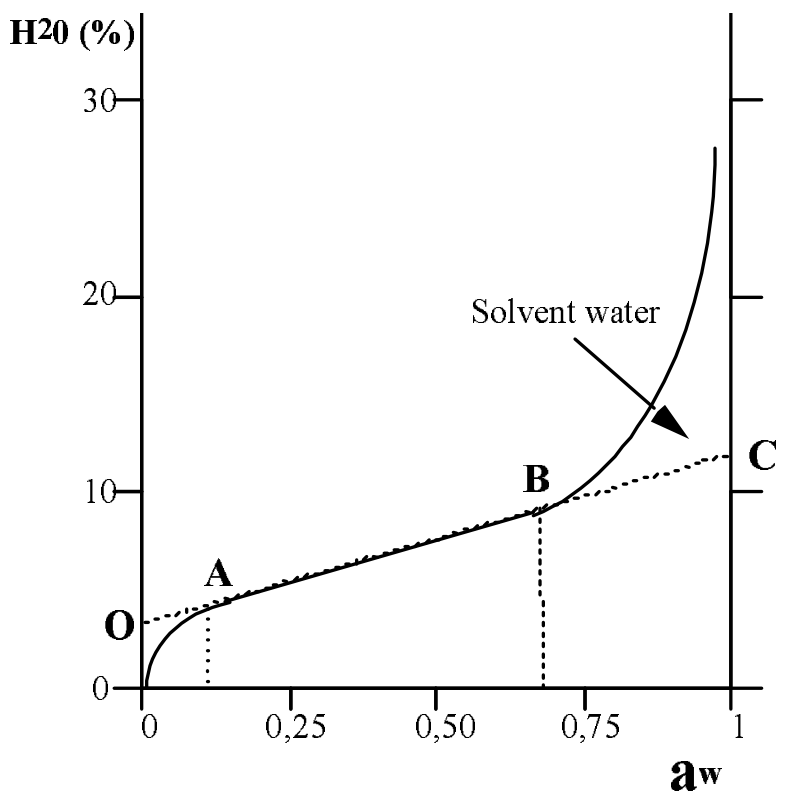


FIGURE 7

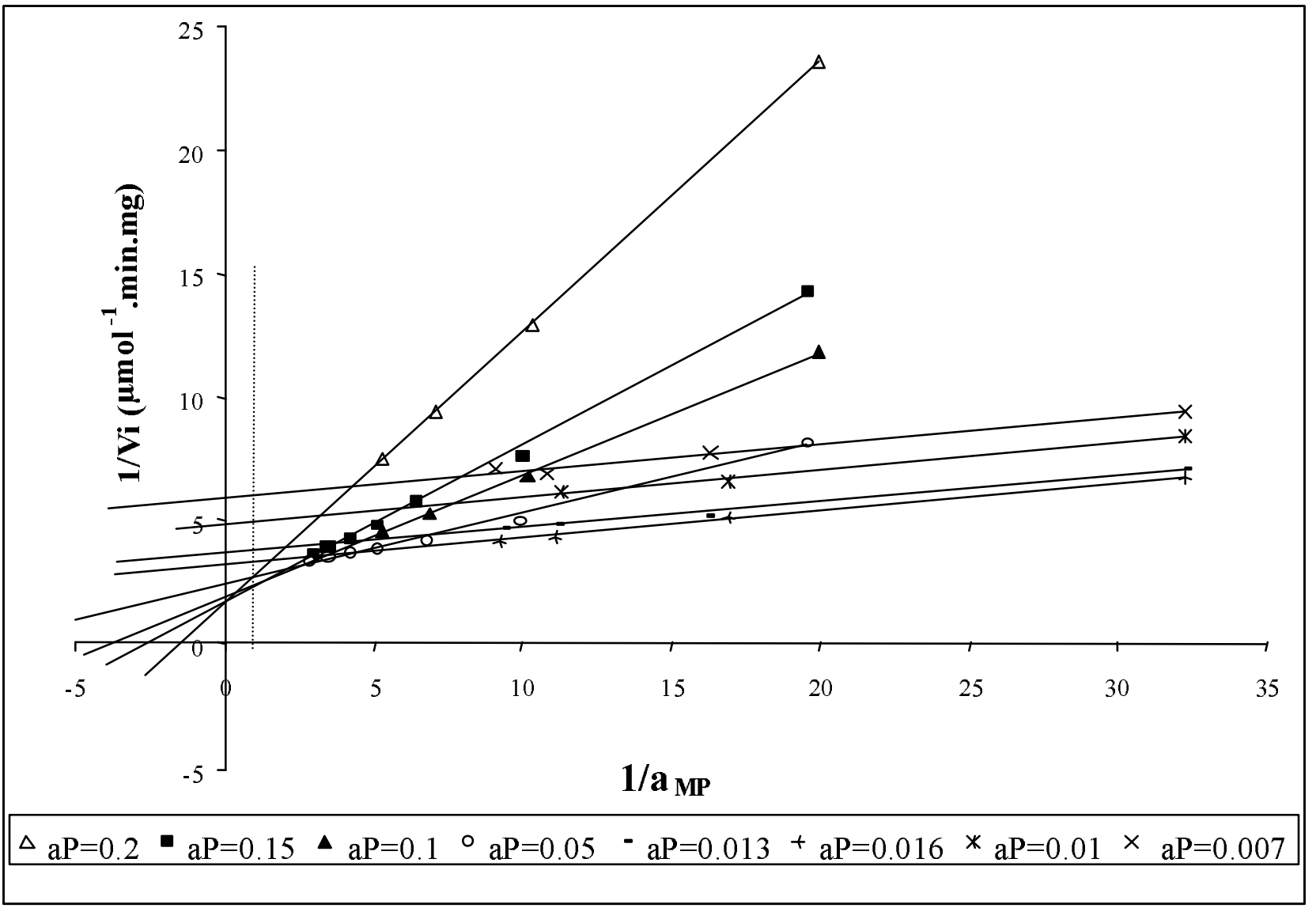


FIGURE 8

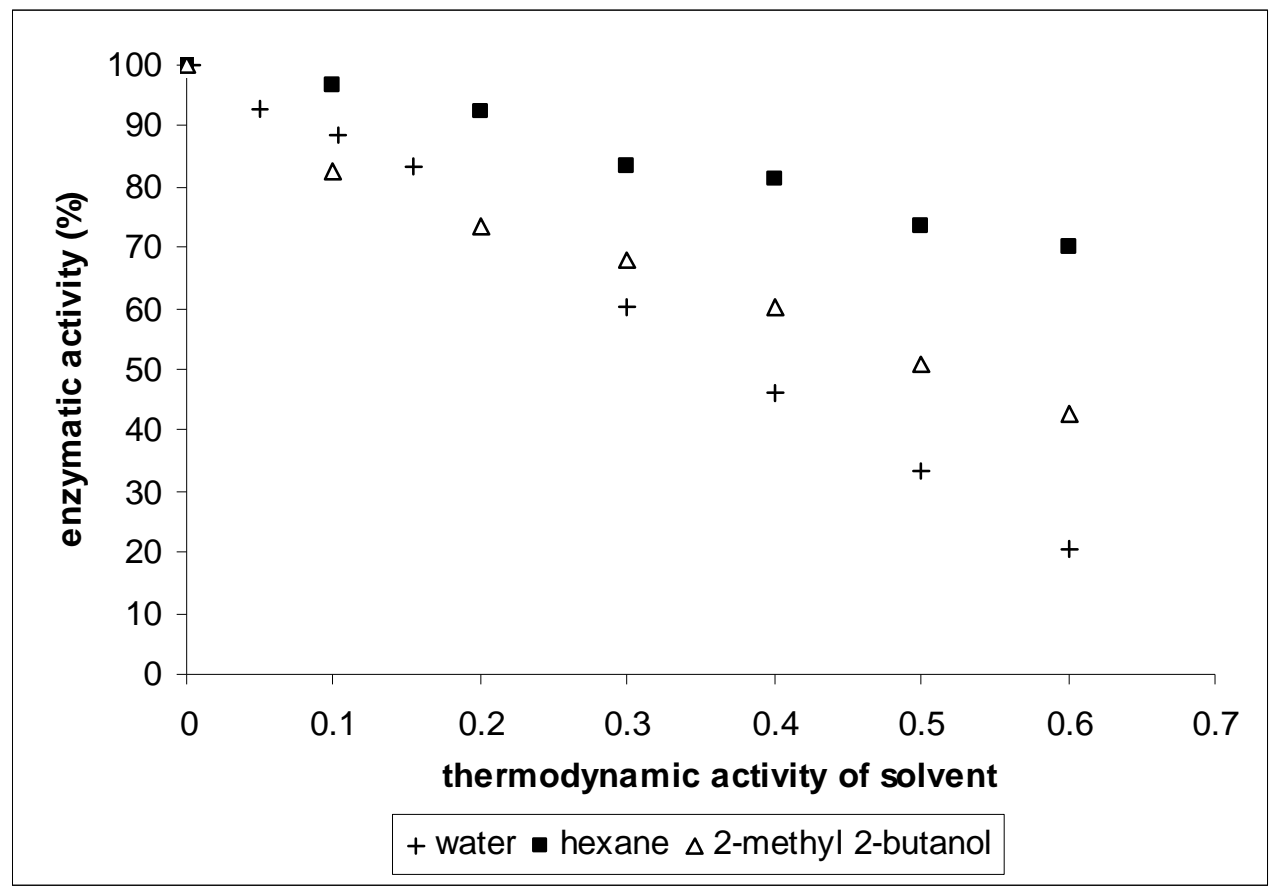


FIGURE 9

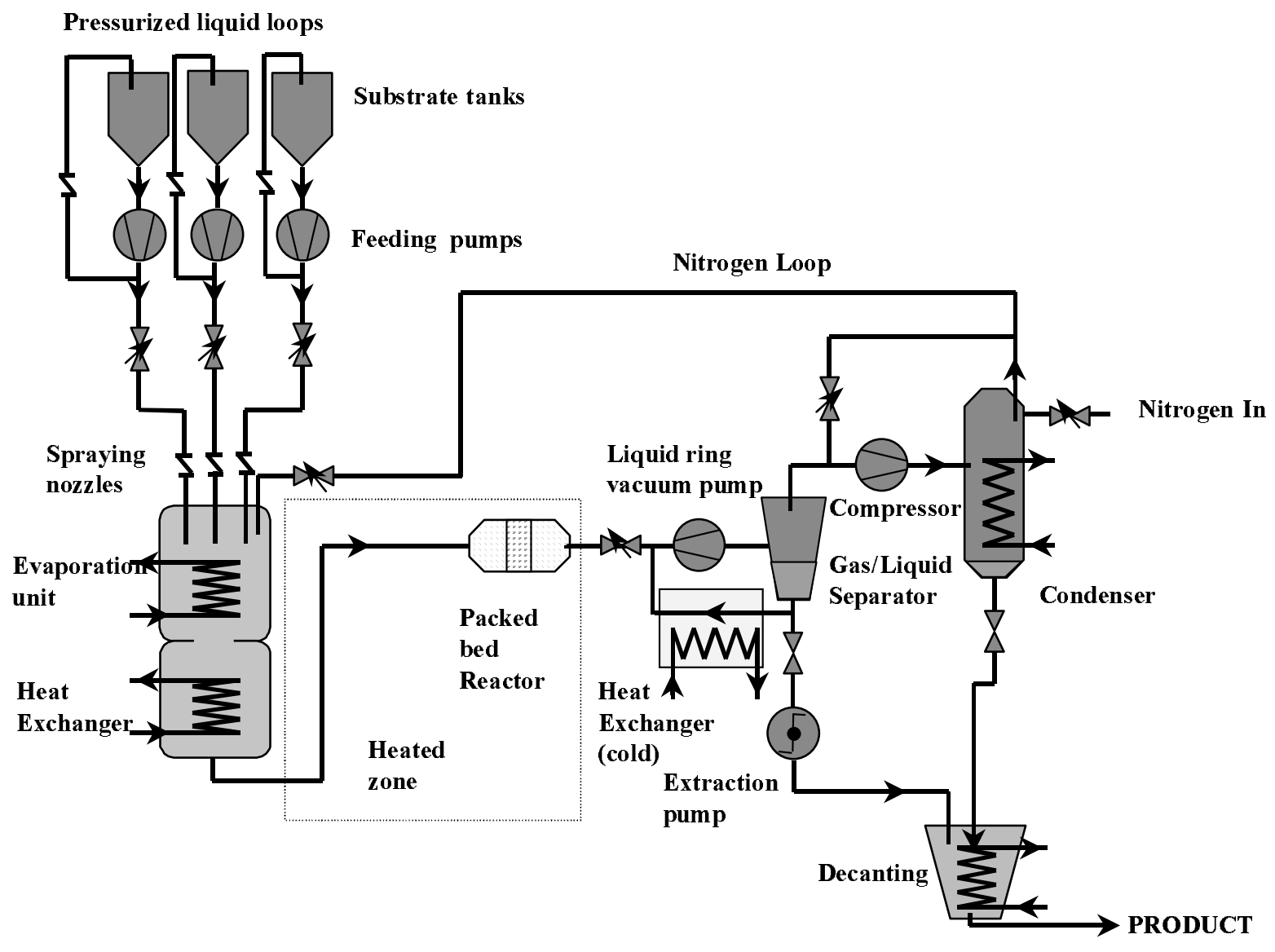


FIGURE 10

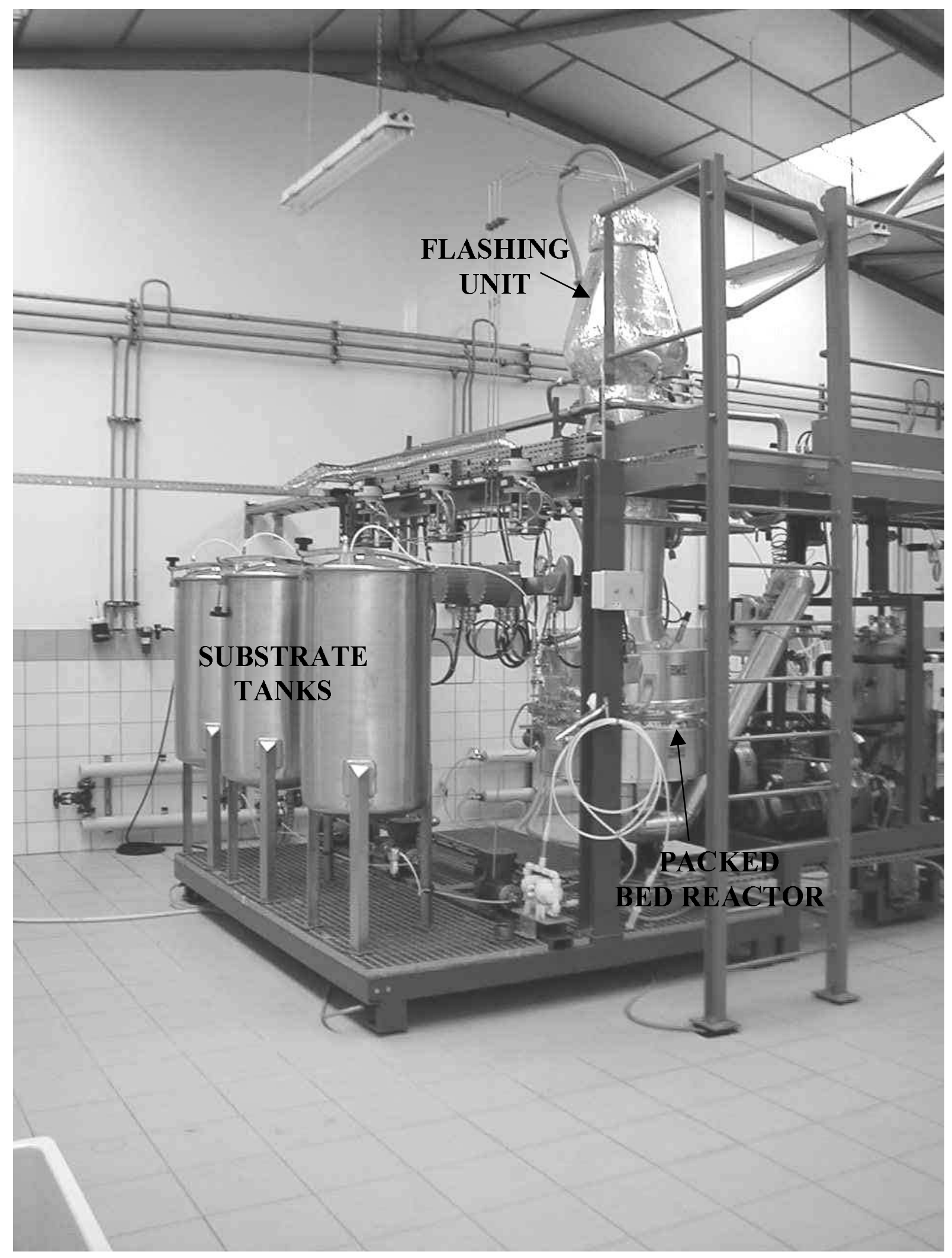


FIGURE 11

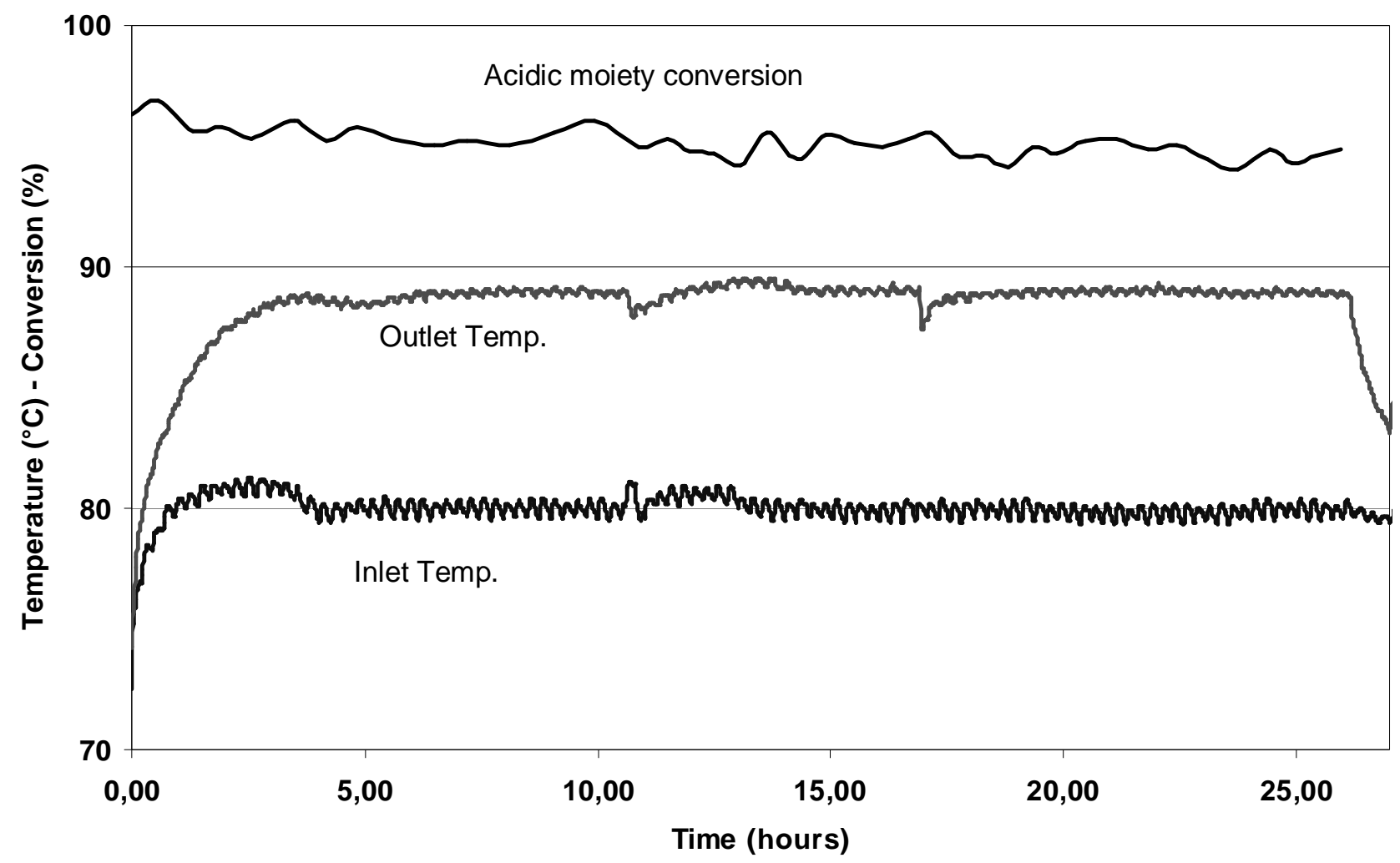


FIGURE 12

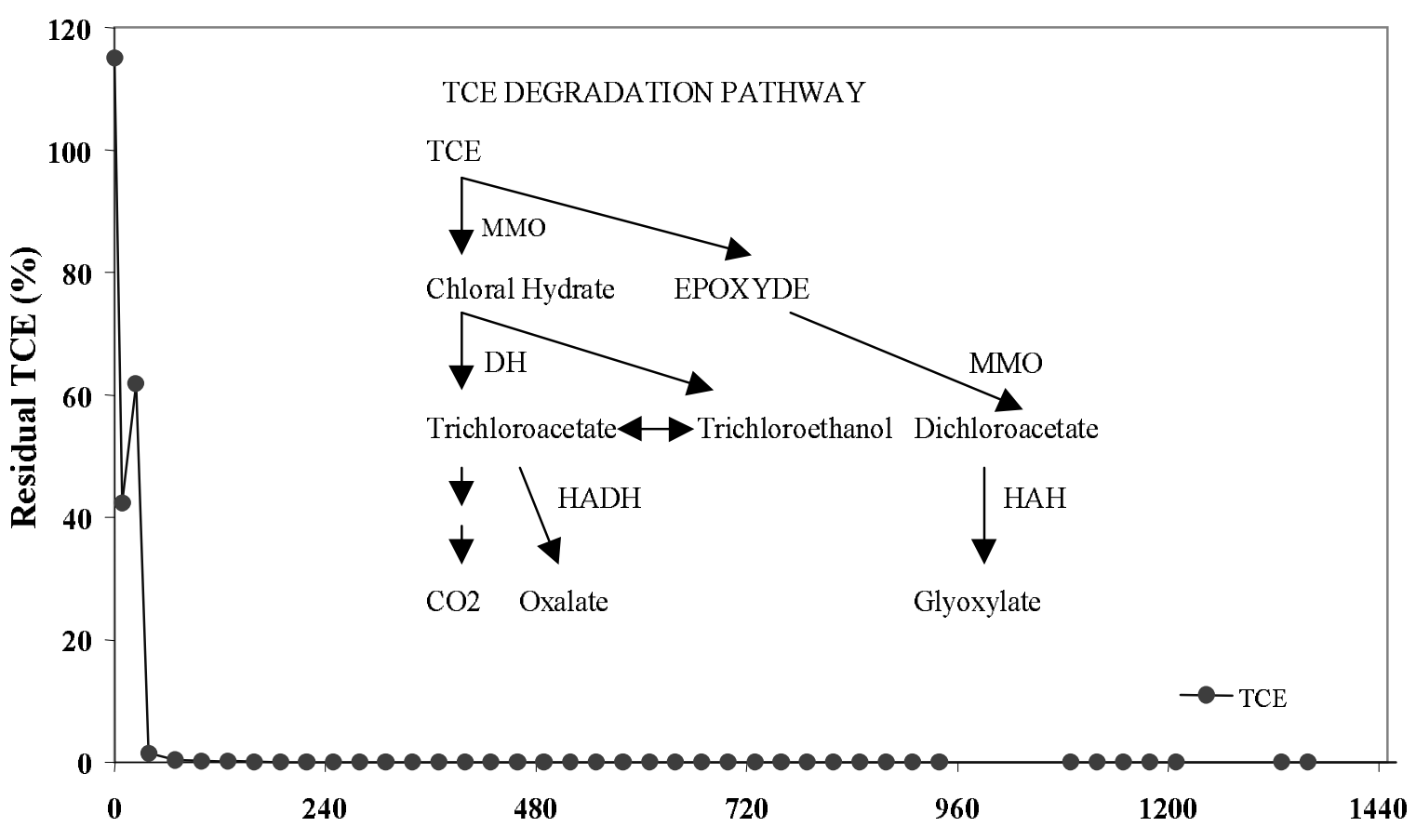

Time (min) 